\title{
ПОСЛЕДОВАТЕЛЬНОСТЬ ЖИЗНЕННЫХ СОБЫТИЙ У РОССИЙСКИХ МУЖЧИН, СЛУЖИВШИХ И НЕ СЛУЖИВШИХ В АРМИИ *
}

\author{
ЕКАТЕРИНА МИТРОФАНОВА, АЛЁНА АРТАМОНОВА
}

\begin{abstract}
На данных двух репрезентативных для России обследований - «Человек, семья, общество» (использовалось для основного анализа) и «Российский мониторинг экономического положения $u$ здоровья населения» (использовалось для дескриптивного анализа) - исследованы жизненные пути российских мужчин, проходивших и не проходивших военную службу по призыву. Сравнивались возрасты и последовательности наступления первых соџиоэкономических (работа, образование, отделение от родителей) и демографических (брак, партнерство, ребенок) событий $и$ сочиодемографические «портреты» служивиих и не служивиих мужчин к возрасту 15 лет и до момента проведения обследования (2013 г.).

Сравнение «портретов» служивших и не служивших в армии мужчин показывает, что механизм отбора в армию изменился. Если раньше единственным различием между служивиими и не служивиими было состояние здоровья, то в современной России в армию идут в основном те, кто не может избежать этого: дети родителей с более низким соџиальным положением на момент сочииализаџии ребенка (без высшего образования, не на высоких должностных позициях). Мужчины, прошедшие срочную службу, чаще живут отдельно, нежели те, кто не служил. Среди них высока доля работающих, в то время как среди не служивших выше доля учащихся. Анализ наступления событий показал, что для тех, кто прошел службу в армии, переход во взрослую жизнь начинается раньше и проходит интенсивнее. К 35 годам мужчины, служившие в армии, имеют больше событий всех типов, особенно демографических.
\end{abstract}

Ключевые слова: армия, срочная служба, демографическое поведение, работа, образование, отделение от родителей, брак, партнерство, Россия, жизненный путь, анализ последовательностей (sequence analysis).

\section{ВВЕДЕНИЕ}

В настоящее время тема службы в армии, а именно ее влияние на жизненный путь мужчины, остается малоизученной. Существующие в этой области исследования можно разделить на два основных направления: первое основано на утверждении, что служба в армии делает из юноши мужчину [Градосельский 2005; Данилова 2005; Михель 2001], другое доказывает, что служба в армии - потерянное зря время [Смирнов 2009; Суханова 2014]. Данные суждения зачастую представляют собой субъективные точки зрения авторов и не имеют в своей основе репрезентативного эмпирического материала.

ЕКАТЕРИНА СЕРГЕЕВНА МИТРОФАНОВА. НАЦИОНАЛЬНЫЙ ИССЛЕДОВАТЕЛЬСКИЙ УНИВЕРСИТЕТ «ВЫСШАЯ ШКОЛА ЭКОНОМИКИ» (РОССИЯ). Е-mail: emitrofanova@hse.ru

АЛЁНА ВЯЧЕСЛАВОВНА АРТАМОНОВА. НАЦИОНАЛЬНЫЙ ИССЛЕДОВАТЕЛЬСКИЙ УНИВЕРСИТЕТ «ВЫСШАЯ ШКОЛА ЭКОНОМИКИ» (РосСИЯ). E-mail: aartamonova@hse.ru

СТАТЬЯ ПОСТУПИЛА В РЕДАКЦИЮ В СЕНТЯБРЕ 2015 Г.

* СТАТЬЯ ПОДГОТОВЛЕНА В ХОДЕ ПРОВЕДЕНИЯ ИССЛЕДОВАНИЯ № 16-05-ОО11 «РАЗРАБОТКА И АПРОБАЦИЯ МЕТОДИК АНАЛИЗА ДЕМОГРАФИЧЕСКИХ ПОСЛЕДОВАТЕЛЬНОСТЕЙ» В РАМКАХ ПРОГРАММЫ НАУЧНЫЙ ФОНД НАЦИОНАЛЬНОГО ИССЛЕДОВАТЕЛЬСКОГО УНИВЕРСИТЕТА «ВЫСШАЯ ШКОЛА ЭКОНОМИКИ» (НИУ ВШЭ)» В 2016 Г. И С ИСПОЛЬЗОВАНИЕМ СРЕДСТВ СУБСИДИИ НА ГОСУДАРСТВЕННУЮ ПОДДЕРЖКУ ВЕДУЩИХ УНИВЕРСИТЕТОВ РОССИЙСКОЙ ФЕДЕРАЦИИ В ЦЕЛЯХ ПОВЫШЕНИЯ ИХ КОНКУРЕНТОСПОСОБНОСТИ СРЕДИ ВЕДУЩИХ МИРОВЫХ НАУЧНООБРАЗОВАТЕЛЬНЫХ ЦЕНТРОВ, ВЫДЕЛЕННОЙ НИУ ВШЭ. 
Взгляд на срочную службу как важное событие в жизни мужчины обусловлен тем, что молодые люди уходят в армию в 18 лет - в том возрасте, когда и с юридической, и с психологической точки зрения они только начинают обретать статус взрослого, самостоятельного человека. Находясь вдали от дома, привычной обстановки, в течение года-двух они учатся быть самостоятельными в быту, но в то же время подчиняться приказам, соблюдать субординацию и отстаивать свое место в очень специфичном коллективе. Это сложное сочетание воздействий на еще молодого человека не может не отразиться на его мировоззрении, отношении к разным аспектам жизни.

В силу ограниченности данных наше исследование не ответит на вопрос о направленности причинно-следственной связи: влияет ли служба в армии на жизненный путь мужчины или в армию попадают мужчины, изначально предрасположенные к определенной модели социодемографического поведения. Для того чтобы делать выводы относительно казуальности, необходимо иметь срез нормативно-ценностных установок и событий в жизни на момент начала службы в армии (или 18-летия для не служивших) и после завершения перехода во взрослую жизнь. Мы располагаем данными только о датах наступления ключевых событий жизни, фактом службы в армии и рядом вспомогательных переменных, полученных из обследования «Человек, семья, общество» (ЧСО) в 2013 г. [Малева и др. 2014; ЧСО 2013].

C помощью метода анализа последовательностей (Sequence analysis - SA) было изучено, как различаются фактические жизненные пути служивших и не служивших в армии мужчин. Не делая выводов о казуальности, мы зафиксировали сами различия, что является важным шагом на пути понимания феномена службы в армии в России. Такого детального изучения данных о службе в армии в контексте жизненного пути ранее не проводилось.

Основная цель исследования - изучение различий наступления социодемографических событий жизненного пути российских мужчин, служивших и не служивших в армии.

Цель была детализирована следующими задачами:

1. определение межпоколенческих различий в возрастах наступления социодемографических событий для служивших и не служивших в армии;

2. выявление различий в последовательностях наступления социодемографических событий для служивших и не служивших в армии;

3. составление «портретов» мужчин, служивших и не служивших в армии, в возрасте 15 лет и на момент проведения опроса (2013 г.)

Прежде чем перейти к рассмотрению результатов решения поставленных задач, необходимо описать структуру данной работы. В первом разделе речь идет об особенностях службы в армии в мире и России, а также рассматривается опыт социологов и демографов в изучении службы в армии как этапа жизненного пути. Второй раздел посвящен особенностям баз данных, на которых построено исследование. В финальной части работы представлены полученные результаты. 


\section{СЛУЖБА В АРМИИ В КОНТЕКСТЕ ИСТОРИИ}

Всего в мире существует несколько форм комплектации армии военнослужащими:

- наемная или контрактная армия, в которой военнослужащие добровольно служат по контракту и получают за это заработную плату;

- воинская повинность или призывная армия, предполагающая всеобщую или выборочную (затрагивающую только мужчин) повинность;

- милиционная или добровольческая армия, в мирное время состоящая только из учетного аппарата и командного состава; воинская служба - кратковременные военные сборы.

В разные периоды времени наибольшую популярность приобретает то один, то другой способ формирования армии. Долгое время в Европе и в мире господствовала наемная армия, но в 1798 г. во Франции появляется армия по призыву для того, чтобы защитить только появившуюся республику от атак соседних государств. Согласно вышедшему в тот год закону все неженатые бездетные французские мужчины, начиная с 20-летнего возраста, призывались на воинскую службу на 5 лет. Духовенство, рабочие, занятые на военных предприятиях, студенты отдельных университетов и чиновники освобождались от службы. Зажиточные французы могли избежать призыва благодаря механизму жеребьёвки: при наличии финансовых возможностей вытянувшие жребий могли купить на службу кого-то вместо себя [Forrest 1989]. Постепенно воинская повинность стала показывать более высокую эффективность по сравнению с господствующей на тот период в Европе практикой содержания наемной армии. Это было вызвано тем, что призыв позволял в случае начала военных действий за короткий промежуток времени мобилизовать большое количество пребывающих в резерве, что было актуально в периоды Первой и Второй мировых войн, начала «холодной войны» между странами Организации Североатлантического договора и Организации Варшавского договора. Однако в начале XXI века после этих крупных войн большинство стран стало снова переходить к наемной, контрактной армии [Shearer 1998].

В каждой стране армия комплектуется, исходя из многих факторов: приоритетов безопасности нации, характера внешних угроз и экономических возможностей, но одним из главных можно назвать демографическую ситуацию. Ярким примером влияния демографических волн на степень жесткости законодательства, регулирующего набор на военную службу, является опыт России.

В 1925 г. ранее добровольное прохождение службы в армии стало обязательным для всех трудящихся мужчин СССР. Служба в вооруженных силах рассматривалась как почетная обязанность и была закреплена в Конституции как священный для каждого мужчины долг защиты Отечества [Основной закон (Конституция) СССР 1936: ст.132, 133]. На службу призывались мужчины 19-40 лет, относящиеся к классу трудящихся. Срок службы составлял 2-4 года (в зависимости от рода войск). В 1939 г. в СССР был принят закон «О всеобщей воинской обязанности», отменяющий запрет на призыв детей бывших офицеров, казаков, духовенства, раскулаченных крестьян, купцов, дворян, фабрикантов. Появились отсрочки по факту болезни и по семейным обстоятельствам. В 1946-1948 гг. 
призыв не осуществлялся, так как все были заняты в восстановительных работах. В 1949 г. срок службы увеличен до 3-4 лет, а призывной возраст снижен до 18 лет.

Из-за снижения рождаемости во время войны в первой половине 60-х годов когорта 18-летних была малочисленной, что вызвало проблемы с комплектованием вооруженных сил. Чтобы нивелировать образующийся недобор рекрутов, в армию на 3 года (в качестве офицеров) стали призывать выпускников вузов. В 70-е годы, когда поколение рекрутов снова стало многочисленным, срок службы снова увеличился до 2-3 лет, а перечень отсрочек по семейным обстоятельствам был существенно расширен. Также особо важные министерства и ведомства получили права на особый воинский учет, что позволяло не призывать нужных данным министерствам специалистов на воинскую службу [Градосельский 2005]. После вторжения Советской Армии в Афганистан в 1979 г. возникла необходимость в увеличении численности военнослужащих, для чего в законодательство, регулирующее комплектование армии, были внесены изменения, расширяющие категории лиц, подлежащих призыву. В середине 80-х, когда 18-летнего возраста достигают малочисленные когорты, действие отсрочек для продолжения обучения приостанавливается, сокращается число министерств и ведомств, имеющих право на особый воинский учет. Но как только призывной контингент снова начинает расти, отсрочки возвращают. После распада СССР и сокращения численности армии число отсрочек существенно возрастает, а с 2007 г. срок службы в армии снижается до 1 года.

\section{СЛУЖБА В АРМИИ СЕГОДНЯ}

На сегодняшний день наименее популярный вид армии - милиционная. Она существует только в Швейцарии. Всеобщая воинская повинность теряет свое лидерство, сохраняясь лишь в небольшом числе стран ${ }^{1}$. Все большее распространение приобретает контрактная армия благодаря сразу нескольким её преимуществам. Во-первых, в добровольной армии служат люди, выбравшие военную карьеру осознанно, а не призывники, думающие о скорейшем отбытии воинской повинности. Во-вторых, контрактная армия снижает текучесть кадров, позволяя сохранять ценные человеко-часы, которые уходят на подготовку всё новых призывников. Повышение квалификации военнослужащих создает условия для обеспечения их передовым оборудованием и техникой. В-третьих, профессионализация армии способствует тому, что молодые люди могут планировать наступление ключевых стартовых событий жизни: получение образования, трудовую деятельность, вступление в брачно-партнерские союзы, начало прокреативного поведения в соответствии с их собственными предпочтениями [Friedman 1967].

Большинство стран мира, включая Россию, переходят к комбинированному способу комплектации армии, сочетающему в разных пропорциях призыв и службу по контракту. Например, в странах Североатлантического альянса контрактники составляют порядка 45\% от общей численности военнослужащих: в ФРГ - 55\%, в Греции и Норвегии - около $30 \%$, в Дании и Бельгии $-60-65 \%$.

\footnotetext{
${ }^{1}$ Россия, Белоруссия, Израиль, КНДР, Швейцария, Финляндия, Австрия, Эстония.
} 
В России в 1998 г. был принят закон «О воинской обязанности» (ФЗ №53 от 28.03.1998), в главе V которого были перечислены условия заключения контракта и поступления на добровольную военную службу. За 17 лет существования такого варианта службы в армии численность контрактников возросла до $50 \%$ от общего числа военнослужащих [РБК 2015]. Д.А. Медведев, будучи главой государства, заявил: «Мы приняли, по сути, политическое решение о том, чтобы в спокойном режиме продвигаться в сторону профессиональной армии. При этом мы сохраним комплектование и за счет призыва, и за счет набора контрактников. Призыв останется, но служить пойдут только те, кто считает это для себя исключительно важным и необходимым. Все остальное будут делать люди, принятые по контракту» [Форбс 2011]. То есть руководство страны понимает приоритеты времени: в век стремительного развития технологий и колоссального прироста информации год отсутствия человека в профессиональной среде - это весьма существенная потеря для его человеческого капитала. У современных молодых людей появляется шанс инвестировать это время в свое развитие, если они не делают осознанный выбор в пользу военной службы. Конечно, в России еще продолжает действовать всеобщий воинский призыв, но появляется гораздо больше легальных (и нелегальных) способов его избежать. Все это дает возможность молодым людям, которые избирают и не избирают для себя военное дело основной профессией, настраивать календарь наступления событий своей жизни в большем соответствии со своими приоритетами.

\section{СЛУЖБА В АРМИИ КАК ЭТАП ЖИЗНЕННОГО ПУТИ}

Концепция жизненного пути получила развитие с 20-х годов прошлого столетия. Первыми воспринимать жизнь не как цикл, а как путь стали психологи [Бочавер 2008]. Затем с 1975 г. концепция начала развиваться в рамках социологических наук и стала по-настоящему междисциплинарной и парадигмальной [Ежов 2005; Рождественская 2012: 21].

Основное отличие «пути» от «цикла» в том, что жизнь перестает восприниматься как череда привязанных к возрасту этапов, предначертанных человеку [Кон 1999]. Жизненный путь - это результат персональных выборов индивида в разных сферах жизни. Здесь также есть этапы, но не возраст является пропуском на очередную ступень, а достижения человека: то, какие статусы он обретает, определяет, на каком этапе жизни он находится. Жизненный путь состоит из статусных переходов - значимых событий, меняющих социальное положение человека, устройство его жизни, социальную идентичность и ролевую принадлежность (например, трудоустройство, завершение получения образования, свадьба, рождение ребенка). Некоторые события имеют еще более сильный эффект, влияя на смену целой траектории или нескольких траекторий жизни. Такие события называются поворотными точками.

Службу в армии можно отнести к подобной поворотной точке, которая может изменить направление развития жизни мужчины сразу в нескольких сферах. В 18 лет, только начиная переход во взрослую жизнь, обретая дееспособность (правовую, трудовую, гражданскую), молодые люди отбывают на срочную службу. Это весьма продолжительное и непростое испытание: разлука с близкими, строгий армейский порядок, субординация, ограничения бытового характера, физические нагрузки, нахождение в исключительно 
мужском коллективе. Одни исследователи считают, что такие испытания закаляют, «делают из мальчика мужчину» [Градосельский 2005; Данилова 2005; Михель 2001], другие полагают, что эти год или два молодой человек гораздо с большей пользой может провести «на гражданке» [Смирнов 2009; Суханова 2014].

Несмотря на всю разность мнений, у них есть одна общая черта: подавляющее большинство работ на тему службы в российской армии выполнено без достаточной опоры на репрезентативный эмпирический материал. Если в других вопросах, где недостает отечественных исследований, можно обратиться к опыту разных стран, то данный сюжет освещен зарубежными коллегами очень слабо ввиду того, что большинство государств перешли на контрактную службу, предполагающую, что служба в армии - не долг перед родиной и не испытание, а оплачиваемая работа. Поэтому исследования, которые выполнены на репрезентативном эмпирическом материале, чаще всего посвящены либо военнослужащим (в период военных действий), а не солдатам-срочникам, либо вопросам, связанным не с демографическим поведением, а со здоровьем, социальными и психологическими особенностями солдат.

При изучении влияния службы в армии на краткосрочное и долгосрочное здоровье призывников [MacLean, Elder 2007; Sampson, Laub 1996] было выявлено, что служба по призыву негативно сказывается на дальнейшем здоровье. Сквозь призму службы в армии также изучалась преступность [Van Schellen, Apel, Nieuwbeerta 2012]. Было обнаружено, что для когорты 1942 г., призванной в армию в начале Вьетнамской войны, служба в армии значительно снизила вероятность совершения преступлений среди несовершеннолетних преступников. Результаты исследования показали, что военная служба способствовала в целом снижению тяжких преступлений в этот период. В исследовании [Britton, Ouimette, Bossarte 2012] установлена связь между прохождением службы в армии и удовлетворенностью жизнью в зависимости от склонности к депрессии: среди не склонных к депрессии мужчин, служивших в армии, на 39\% больше удовлетворенных жизнью, чем среди не служивших.

Одним из тех, кто анализировал влияние службы в армии на демографическое поведение солдат, является Г. Элдер-младший. Сформулированный им (в рамках концепции жизненного пути) принцип «стадии жизни» подразумевает, что влияние исторических событий варьируется в зависимости от этапа жизни человека. Для проверки этого принципа Элдер провел исследование о взаимодействии между военной службой и возрастом, используя данные Oakland Growth Study [Elder 1987]. Он выяснил, что для мужчин, мобилизованных в более позднем возрасте (старше 22), военная служба может разрушить семейные связи и карьеру.

Согласно Элдеру наименьшую личную выгоду военнослужащие извлекают во время участия в военных действиях. Он обнаружил, что частота разводов у американских военнослужащих выше, чем у гражданского населения. При этом важно, в какой отрезок времени был заключен брак: до, во время или после войны. Браки, заключенные до войны, было тяжело сохранить по причине длительного разделения партнеров. Очевидно, что оба партера не остаются прежними во время войны: служащие испытывают все тяжести военного боя, в то время как жены, ждущие их дома, испытывают все тяжести 
экономических лишений, полную ответственность за семью, неведомую им в мирное время. После окончания Вьетнамской войны вернувшиеся домой солдаты демонстрировали стремление как можно скорее создать семью, в отличие от сверстников, которые не принимали участия в войне.

Таким образом, особенности влияния срочной службы в армии на жизненный путь мужчин исследованы недостаточно комплексно и глубоко. В данной работе впервые биографии российских мужчин будут изучены через призму наличия или отсутствия армейского опыта. Это будет сделано на основе репрезентативных российских данных с помощью одного из наиболее продвинутых и перспективных методов - SA.

На основе собранных нами сведений об изменениях в российском законодательстве относительно службы в армии, о влиянии внешних факторов (войн, демографических волн) и о понимании вектора трансформации демографического поведения мы сформулировали следующие гипотезы.

1. Межпоколенческие различия между служившими и не служившими в армии проявятся только для тех, кто был призван после 1991 г. (1973 год рождения - г.р.), поскольку до этого времени возможность избежать призыва была минимальной, и в армию не попадали, в основном, по состоянию здоровья.

2. Долгая разлука с близкими людьми, идеализация жизни «на гражданке» может усилить желание мужчин, вернувшихся из армии, создать свою семью. Мы предполагаем, что в целом интенсивность наступления демографических событий у отслуживших мужчин будет выше.

\section{ИНФОРМАЦИОННАЯ БАЗА ИССЛЕДОВАНИЯ}

В данном исследовании были использованы базы данных двух крупных обследований, репрезентативных для России: «Человек, семья, общество» (ЧСО) и «Российский мониторинг экономического положения и здоровья населения» (РМЭЗ). Первая волна ЧСО проведена в 2013 г. Институтом социального анализа и прогнозирования РАНХиГС [Малева и др. 2014; ЧСО 2013]. В том же году НИУ ВШЭ проведена 22-я волна РМЭЗ [РМЭЗ 2013]. Основной базой является ЧСО, поскольку содержит полную и точную информацию о разных событиях жизненного пути, а также вопрос о службе в армии. РМЭЗ использовали в описательном блоке.

В обследовании ЧСО было опрошено 9500 респондентов (45,3\% - мужчины, 54,7\% женщины), выбранных с помощью многоступенчатой стратифицированной районированной выборки, что с $5 \%$-ной погрешностью позволило достигнуть репрезентативности данных для населения России старше 18 лет. На 3-ей ступени построения выборки районирование проводили по избирательным участкам, поэтому в выборку не попали лица, отбывающие уголовное наказание и временно лишенные права голоса.

В анкете ЧСО присутствовали 2 вопроса, касающиеся службы в армии. Первый вопрос был прямым, сформулированным следующим образом: «Служили ли вы в армии?». 
Положительный ответ на него дали 2952 мужчины, отрицательный - 1381. Второй вопрос (косвенный) касался армии как одной из причин переездов. Только 19\% мужчин указали службу в армии как причину переезда. Количество дат невелико, поэтому анализ был основан на первом вопросе, используемом в дальнейшем в качестве стратифицирующей переменной. Однако у этого вопроса есть недостаток: его формулировка неточна, и положительный ответ могут дать те, кто получил офицерское звание, учась в гражданском вузе, или попал под особый воинский учет.

В обследовании РМЭЗ 2013 г. (была использована полная выборка) вопрос о службе в армии был задан корректнее: «Вы проходили срочную службу в армии, то есть служили по призыву?». В случае положительного ответа задавался еще один вопрос: «С какого по какой год Вы проходили срочную службу в армии?». Всего в базе РМЭЗ 3595 мужчин, прошедших срочную службу, и 2476 - не прошедших.

Несмотря на более детализированную информацию о службе в армии по РМЭЗ, в качестве основной базы данных было выбрано обследование ЧСО. Ключевая причина наличие в нем вопросов относительно дат наступления стартовых событий в разных сферах жизни, которые определяют основное направление данного исследования.

Разница в формулировках вопросов ЧСО и РМЭЗ и погрешности при измерениях привели к возникновению небольших расхождений в распределениях мужчин, прошедших службу в армии. На рисунке 1 представлена доля мужчин, прошедших срочную службу, в численности своей когорты по году рождения. Резкие перепады кривой обусловлены малым числом наблюдений в самых старших и самых молодых возрастах.

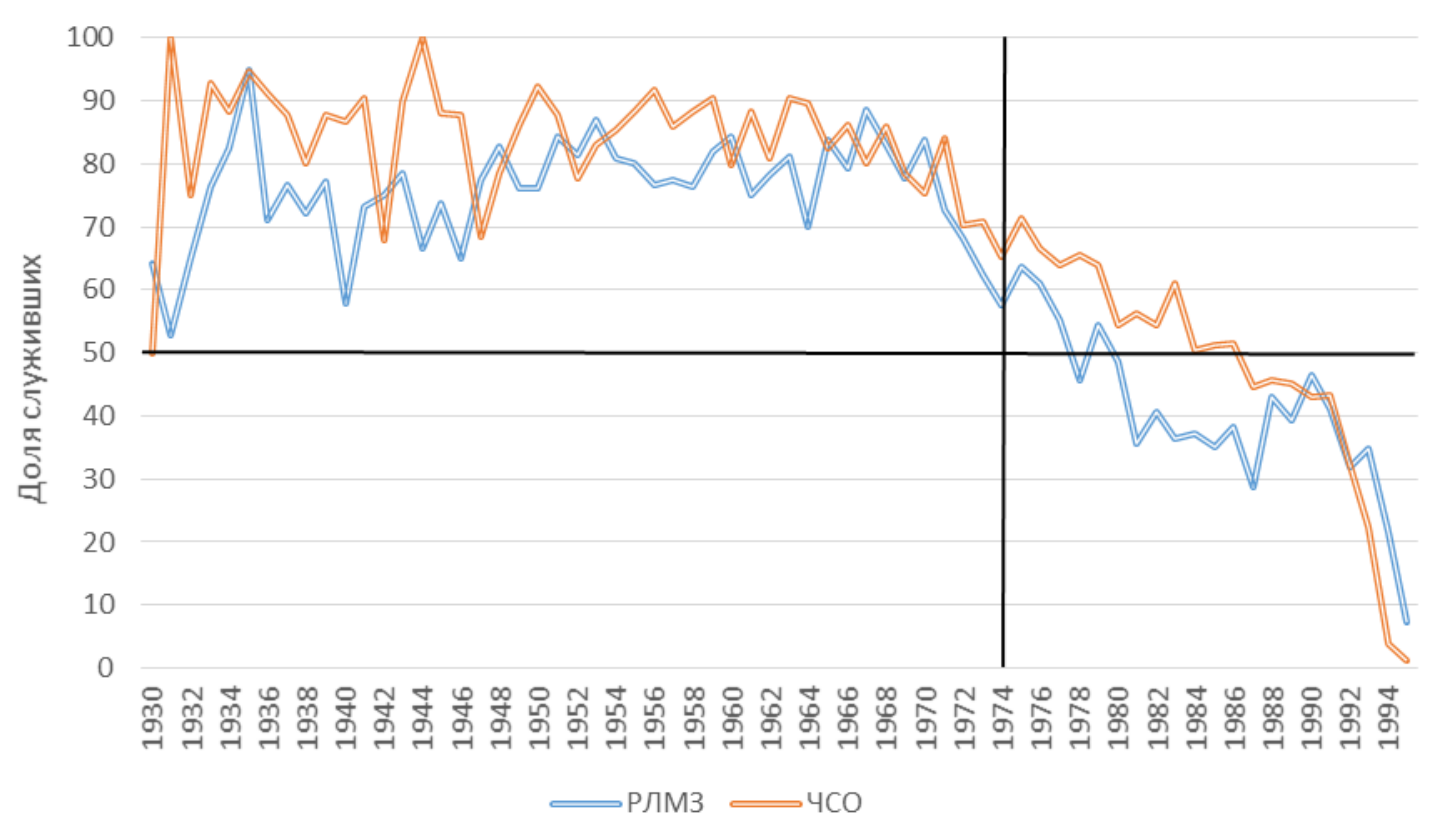

\section{Рисунок 1. Доли служивших в армии (однолетние когорты по году рождения), \%}

Источник: составлено авторами по данным [РМЭЗ 2013, ЧСО 2013].

На рисунке 1 горизонтальной линией выделен уровень 50\%. Выше него - ситуация превышения числа мужчин, прошедших срочную службу, над числом не прошедших ее. 
Ниже него - обратная ситуация. Вертикальной линией выделен 1973 г.р. - поколение, которое достигло 18 лет в 1991 г. в момент распада СССР. До 1987 г.р. по РМЭЗ и 1984 г.р. по ЧСО доля тех, кто призывался, превышала долю тех, кто получал «белый билет». Как видно из графика, система воинского учета в советский период работала безотказно, на учет ставили практически всех дееспособных мужчин призывного возраста. В современной России механизм отбора в армию изменился, доля призывников в численности когорты снизилась до $30 \%$ и меньше.

На рисунке 2 представлено распределение возрастов, в которых юноши отправлялись на службу в армию (по данным [РМЭЗ 2013]). Большинство молодых людей призывалось на воинскую службу по достижении 18-летнего возраста или на следующий год, если дата их рождения была позже осеннего призыва или если они имели отсрочку для окончания среднего или среднеспециального образования. Для поступающих в военные училища делалось исключение, они могли поступить на военную службу в возрасте 17 лет, но таких, судя по гистограмме, было немного. В сумме более $80 \%$ проходивших срочную службу были призваны до 20-летнего возраста.

В 2000-х годах, когда призывного возраста стали достигать самые молодые поколения, наблюдался рост популярности и доступности высшего образования, а также предоставление отсрочек на период обучения. Это привело к снижению доли призываемых в 18-летнем возрасте и сгладило распределение по возрасту призывников.

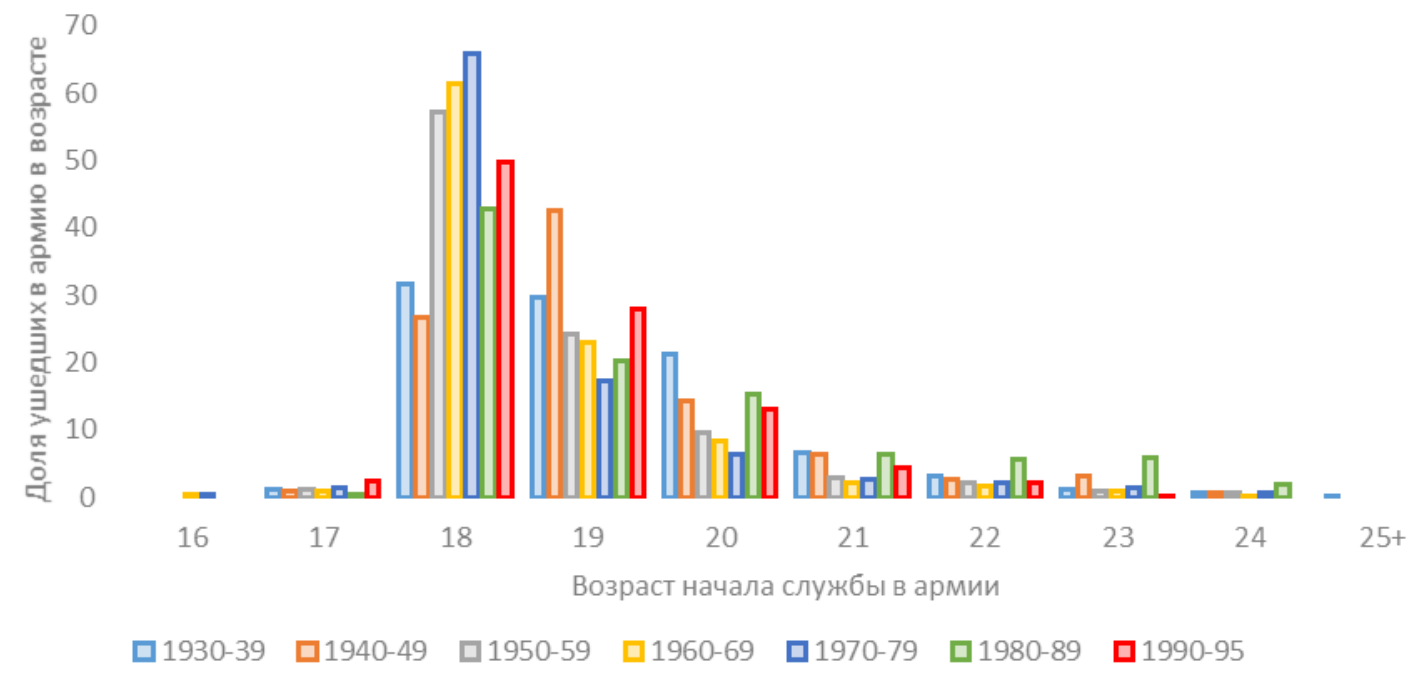

\section{Рисунок 2. Возраст фактического начала службы в армии представителей разных поколений, \%}

Источник: составлено авторами по данным [РМЭЗ 2013].

Считается, что средний возраст наиболее интенсивного формирования ценностнонормативного сознания в отношении к детям и супружеству приходится на 20 -летие юноши [Магун 2009]. Полученный в этот период опыт оказывает влияние на дальнейшую траекторию жизненного пути. Данный период для подавляющего большинства мужчин старше 40-49 лет приходился на срочную службу в армии. Поколения моложе 1970 г.р. призывались уже после перелома в комплектовании вооруженных сил, в результате 
которого выросла доля не служивших и получивших отсрочку, соответственно прошедших период интенсивного формирования ценностно-нормативного сознания не в казармах. С этими же поколениями связывают межпоколенческий слом в семейных ценностях [Попова 2009]. А значит, сокращение доли служивших в армии могло способствовать отходу от традиционных семейных ценностей среди мужчин и стать одним из механизмов начавшегося в России Второго демографического перехода.

\section{ОСНОВНЫЕ РЕЗУЛЬТАТЫ}

\section{Социодемографические «портреты» служивщих и не служивщих в армии}

Как было показано на рисунке 1, численность мужчин, прошедших армию, разнится в зависимости от поколений: если в советское время число призывников превышало число «белобилетников», то в современной России число не служивших превышает число тех, кто отслужил. Причиной может быть то, что в советское время главным основанием для селекции при наборе в армию являлось состояние здоровья призывника, а в современной России механизм селекции изменился: идут служить те, кто не смог «откосить», т.е. юноши из менее обеспеченных семей, те, кто не смог или не захотел получать высшее образование, выходцы из сельских поселений, для которых армия может стать социальным лифтом. Также существует отсрочка для мужчин, имеющих двух детей. Для того чтобы изучить причины, по которым поменялось соотношение служивших и не служивших, и проверить Гипотезу 1, мы построили «портреты» мужчин каждой категории, рожденных до и после 1970 г.

Для составления «портретов» мужчин из опросника ЧСО были выбраны интегральные переменные, характеризующие респондента в детстве и на момент опроса.

1. На момент 15-летия:

- наличие братьев и/или сестер;

- уровень образования родителей;

- категория труда родителей;

- уровень дохода семьи;

- инвалидность, полученная в детстве.

2. На момент опроса:

- уровень образования;

- основной род деятельности;

- владение иностранными языками;

- проживание с родителями;

- наличие инвалидности.

Как и предполагалось в Гипотезе 1, для поколений, рожденных до 1970 г., значимых различий между служившими и не служившими не наблюдается. Единственным исключением являются люди с инвалидностью: их больше среди тех, кто не служил в армии, однако доля таких людей в выборке обследования ЧСО настолько мала, что некорректно делать какие-либо выводы. 
В случае современных поколений ситуация меняется (рисунки 3 и 4) ${ }^{2}$. Если говорить о статистически значимых различиях между служившими и не служившими, то первые это в основном юноши, чьи родители на момент их 15-летия имели профессиональное (в случае отцов), а также среднее полное или ниже (в случае матерей) образование, занятые физическим трудом (рисунок 3 ). «Портрет» современного не служившего юноши на момент его 15-летия выглядит следующим образом: это дети высокообразованных родителейспециалистов высшей квалификации.

\section{Уровень образования родителей}

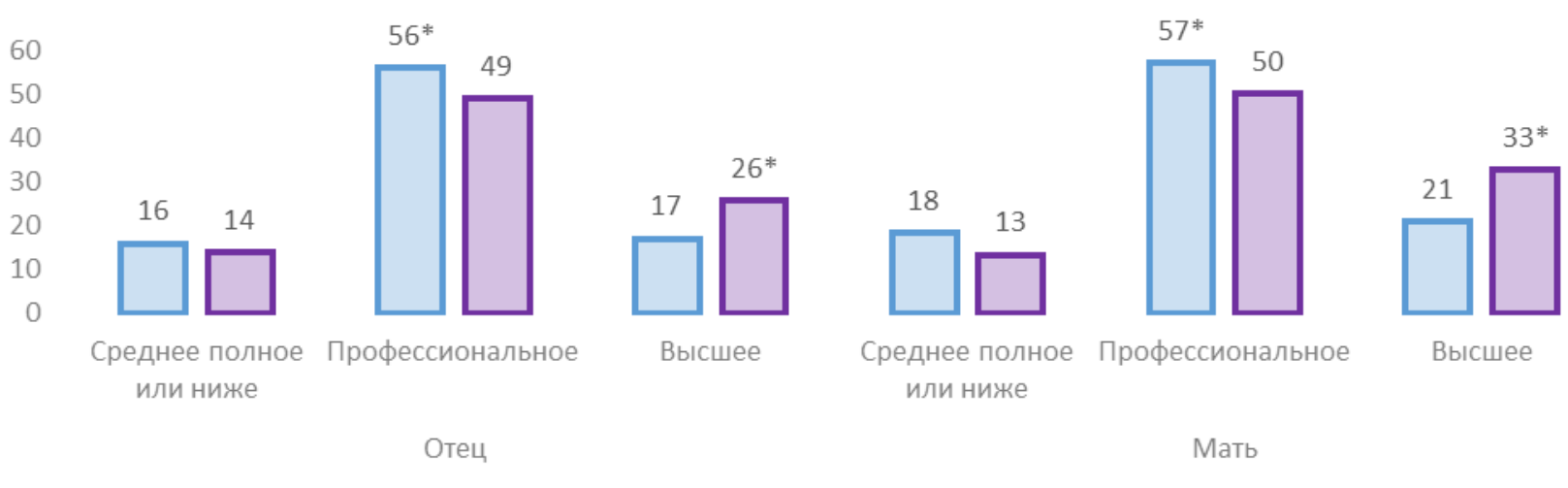

Категория труда родителей

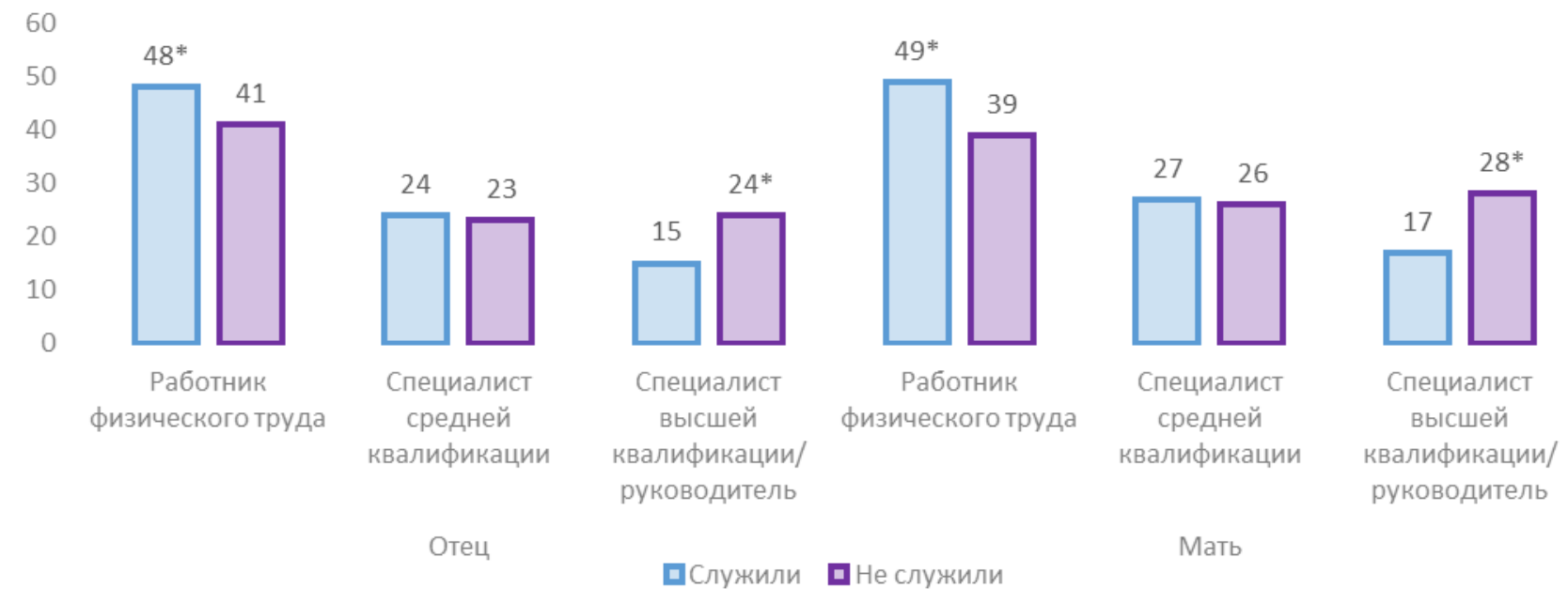

Рисунок 3. Характеристики служивших и не служивших мужчин, рожденных после 1970 г., к возрасту 15 лет, \%

Примечание: * - Доля значимо выпе (95\%).

Источник: составлено авторами по данным [ЧСО 2013].

На момент опроса мужчины, отслужившие в армии, обладают следующим набором характеристик (рисунок 4): они живут отдельно (в то время как не служившие живут с

\footnotetext{
${ }^{2}$ Представлены результаты только по тем переменным, различия по которым оказались значимы. WWW.DEMREVIEW.HSE.RU
} 
обоими родителями или с матерью), работают (не служившие учатся или совмещают работу с учебой), в отличие от не служивших не владеют иностранными языками.

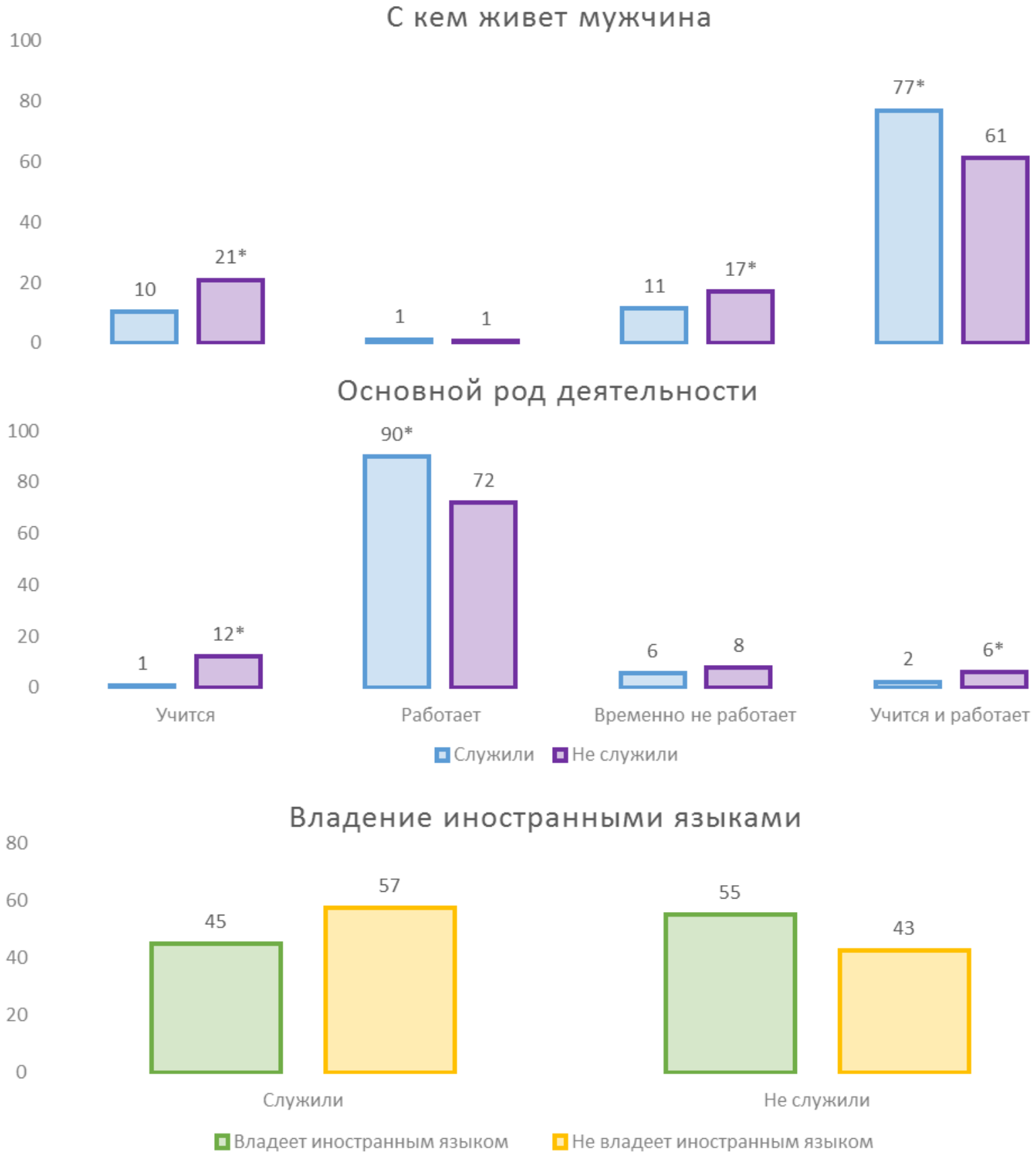

Рисунок 4. Характеристики служивших и не служивших в армии мужчин, рожденных после 1970 г., на момент опроса, \%

Примечание: * - Доля значимо выме (95\%).

Источник: составлено авторами по данным [ЧСО 2013].

Предположение об изменении механизма селекции подтвердилось: до 1970 г. служившие и не служившие в армии мужчины различались только по наличию инвалидности, а различия в молодых когортах наблюдаются по целому ряду показателей. Из характеристик ситуации респондента в детстве значимыми оказались только должность 
и образование родителей. Доход семьи, наличие сибилингов и инвалидность, полученная в детстве, различий не показали. Полученные результаты говорят о том, что именно выгодные социальные связи, проявляющиеся через должность и образованность родителей, а не доход или состояние здоровья, являются причиной, благодаря которой современные молодые люди избегают службы в армии.

Характеристики респондентов после службы в армии различаются по большему спектру показателей: служившие чаще живут отдельно, работают (по состоянию на момент опроса) и не владеют иностранными языками. То есть в целом мужчины, прошедшие «школу жизни» в армии, являются более самостоятельными: они чаще сами себя обеспечивают и живут отдельно. Уровень образования оказался незначим, так как таких барьеров для получения высшего образования, какие были в определенные периоды советского времени, в современной России нет. Однако владение иностранными языками косвенно свидетельствует, что мужчины, избежавшие службы в армии, ориентированы на более качественное образование. Состояние здоровья вновь не различается для прошедших и не прошедших срочную службу. То есть в армии, где изначально главным критерием отбора являлось здоровье призывников, перестают работать механизмы отбора по этому признаку.

\section{Возрастные особенности наступления событий у мужчин}

В данном разделе мы рассмотрим различия в возрастах наступления стартовых социодемографических событий жизненного пути у тех, кто прошел и не прошел службу в армии.

Согласно теории Второго демографического перехода [Jennings, Sullivan, Hacker 2012; van de Kaa 1987; Lesthaeghe 1995; Potârcă, Mills, Lesnard 2013] к маркерам изменений в демографической сфере можно отнести растущую долю разводов, повторных браков, незарегистрированных официально отношений, рост среднего возраста вступления в брак. Все эти изменения задают направление трансформациям в других сферах жизни. В связи с этим для подробного рассмотрения были выбраны следующие стартовые события жизненного пути служивших и не служивших мужчин: первое отделение от родителей, первое трудоустройство, завершение получения образования наивысшего уровня, сексуальный дебют, первое партнерство, первый брак, рождение первого ребенка (таблица 1).

Здесь и дальше в работе будет использована лишь часть массива ЧСО. Это обусловлено тем, что все вопросы из блока «Браки, союзы, дети», представляющие для нас большой интерес, были заданы только респондентам репродуктивного возраста. Поэтому мы вынуждены ограничиться подвыборкой, состоящей из когорт 1970-1995 г.р. (2062 мужчины, из которых 1111 служили, а 951 не служили). Респонденты этих лет рождения призывались на службу начиная с 1987 г., что лишает нас возможности оценить связь службы в армии с демографическими событиями для мужчин, которые попали в периоды стабильно высокого уровня призыва. 
Таблица 1. Средний возраст наступления социодемографических событий

\begin{tabular}{|c|c|c|c|c|c|c|c|}
\hline Поколения & $\begin{array}{l}\text { 1-е отделение } \\
\text { от родителей }\end{array}$ & $\begin{array}{c}1-я \\
\text { работа }\end{array}$ & $\begin{array}{c}\text { Образование } \\
\text { наивысшего } \\
\text { уровня } \\
\end{array}$ & $\begin{array}{c}\text { 1-я } \\
\text { интимная } \\
\text { близость } \\
\end{array}$ & $\begin{array}{c}1-\mathrm{e} \\
\text { партнерство }\end{array}$ & $\begin{array}{c}1-\bar{и} \\
\text { брак }\end{array}$ & $\begin{array}{c}\text { 1-й } \\
\text { ребенок }\end{array}$ \\
\hline \multicolumn{8}{|c|}{ Служившие в армии } \\
\hline $1970-1974$ & 22,2 & 20,8 & 19,6 & 20,0 & 23,2 & 24,1 & 25,8 \\
\hline $1975-1979$ & 21,6 & 21,2 & 19,7 & 19,3 & 22,8 & 24,9 & 25,9 \\
\hline 1980-1984 & 21,1 & 20,9 & 19,4 & 18,7 & 21,5 & 23,8 & 24,5 \\
\hline 1985-1989 & 19,9 & 20,4 & 19,2 & 18,1 & 20,7 & 22,7 & 23,2 \\
\hline 1990-1994 & $19,1 *$ & 19,7 & 18,2 & 17,1 & 18,1 & 20,3 & 19,8 \\
\hline \multicolumn{8}{|c|}{ Не служившие в армии } \\
\hline 1970-1974 & 22,5 & 21,0 & 20,3 & 19,4 & 22,7 & 25,3 & 25,5 \\
\hline $1975-1979$ & 22,2 & 21,4 & 19,8 & 19,7 & 22,7 & 24,7 & 25,8 \\
\hline $1980-1984$ & 21,1 & 20,7 & 20,0 & 19,1 & 21,2 & 24,0 & 24,9 \\
\hline $1985-1989$ & 20,4 & 20,2 & 19,4 & 18,3 & 20,5 & 22,6 & 23,0 \\
\hline 1990-1994 & 18,4 & 19,4 & 17,8 & 16,9 & 17,9 & 20,2 & 20,8 \\
\hline
\end{tabular}

Примечание: *- Значимо выше для представителей того же поколения, не служивщих в армии.

Источник: Составлено авторами по данным [ЧСО 2013].

Возрасты наступления стартовых социоэкономических и демографических событий значимо не различаются для служивших и не служивших в армии, однако интересно посмотреть на общие тренды, одинаковые для обеих групп мужчин. Прежде чем сделать это, стоит отметить, что некоторым представителям самого молодого поколения на момент опроса не было и 20 лет, что сказалось на величине средних возрастов и затруднило сравнение с показателями, рассчитанными для предшествующих поколений.

Наблюдается сильное снижение возраста отделения молодых людей от родителей, однако это эффект молодости когорт, так как исследование, выполненное на похожих данных, показывает откладывание этого события молодежью [Долгова, Митрофанова 2015]. В случае начала трудовой карьеры явного снижения возраста не происходит: мужчины начинают работать примерно в 20-21 год. Средние возрасты завершения получения образования наивысшего уровня показывают, что большинство мужчин (вне зависимости от службы в армии и принадлежности к поколению) имеют среднее образование, так как получают его до возраста 20 лет. Незначительные колебания могут быть вызваны изменениями в системе образования в стране, в частности количеством лет обучения в школе.

Средний возраст сексуального дебюта снижается к более молодым поколениям. Данная тенденция началась еще в послереволюционные годы [Денисенко, Далла Зуанна 2001] и, как видно из таблицы, продолжается до сих пор. При этом скорость снижения этого возраста у служивших и не служивших в армии существенно не различается. Поколения, которые родились после 1960 г., чаще начинают совместную жизнь с сожительства, а не с брака [Артамонова, Митрофанова 2016; Митрофанова 2010]. Часто такой союз принимает форму пробного брака и может распасться или перерасти в брак [Захаров 2007]. Это косвенным образом подтверждается тем, что возраст первого брака превышает возраст вступления в первое сожительство. К началу 1990-х годов в России разница в возрастах наступления сексуального дебюта, вступления в первый брак и рождения первого ребенка оказалась минимальной. Для представителей «советских» поколений снижение возраста сексуального дебюта в условиях отсутствия современных средств контрацепции часто 
приводило к незапланированной беременности, которая прикрывалась браками [Захаров 2007], однако согласно классификации Т.А. Гурко [Гурко 2001] незапланированная беременность - далеко не единственная причина заключения брака. Брак, по её мнению, может быть вызван стремлением:

- юридически зарегистрировать наступление добрачной беременности;

- легализовать существующе любовные, сексуальные отношения;

- психологически отделиться от родителей;

- вступить в брачный статус для постановки в очередь на жилье, на предоставление семейного общежития;

- закрепиться в городе;

- быть как все, «вернулся из армии - пора жениться»;

- иметь семью, детей.

Существование мотивации жениться после возращения из армии подтверждается увеличением случаев заключения брака в возрасте 22 лет для служивших.

Как показал анализ средних возрастов наступления социодемографических событий, мы сталкиваемся с большими погрешностями в оценке показателей для молодых поколений, так как большая часть этих когорт еще не сделала своих выборов в разных сферах жизни, а те, кто сделал, пережили события в заведомо ранних возрастах. Чтобы нивелировать эти недостатки стандартных статистических методов, мы изучили последовательности наступления событий, которые дают более полную и объективную картину происходящих изменений.

\section{Анализ последовательностей наступления социально-демографических событий для служивших и не служнвших мужчин}

Анализ последовательностей наступления событий (SA) - это один из наиболее передовых методов анализа событий жизни, дающий уникальную информацию, которую невозможно получить другими методами. SA позволяет работать не с отдельными событиями, а с цепочкой довольно большого числа событий [Abbott 1995; Billari 2001; Billari, Piccarreta 2005; Ritschard, Oris 2005]. Чтобы представить события в виде последовательности, необходимо перейти от формата событий к формату статусов, представляющему набор букв, в которых закодировано состояние человека в каждой из рассматриваемых сфер жизни на определенный момент времени. В данной работе за единицу времени был взят месяц. Стартовой точкой являлось 15-летие, а конечной - 35-летие, т.е. для каждого респондента был построен отрезок жизненного пути длиной в 240 месяцев. Мы ограничили период наблюдения 35-летием, чтобы уравнять шансы разных поколений на наступление событий и исключить маргинальные случаи (так как первые события чаще всего происходят в первой половине жизни).

Каждый статус отражает положение респондента в трёх сферах-измерениях: репродуктивной, матримониальной, социоэкономической. Если первые 2 измерения имеют всего несколько комбинаций, что будет показано ниже, то 3 социоэкономических события дают 26 комбинаций (в том числе учитывается одновременное наступление событий). Для 
того чтобы сократить число итоговых статусов, сначала был проведен пробный анализ, который показал, какие события встречаются чаще, а какие - реже. Для получения максимального представления о последовательностях в парах событий мы акцентировали внимание на первом событии, а в тройках событий - на последнем. Разбиение каждого измерения на категории представлено списком ниже, а группировка в статусы - в таблице 2 .

1. Репродуктивная сфера:

- нет ребенка;

- есть минимум 1 ребенок.

2. Матримониальная сфера:

- одинок;

- есть опыт проживания минимум в одном партнерстве;

- есть опыт проживания минимум в одном браке.

3. Социоэкономическая сфера:

- нет социоэкономических событий или есть одно из событий: отделение от родителей, опыт работы, получение образования наивысшего уровня;

- 2 события: отделение от родителей, затем одно событие;

- 2 события: трудоустройство на первую работу, затем одно событие;

- 2 события: завершение получения образования наивысшего уровня, затем одно событие;

- 2 события наступили одновременно;

- 3 события: 2 события наступили одновременно или последовательно, затем отделение от родителей;

- 3 события: 2 события наступили одновременно или последовательно, затем трудоустройство;

- 3 события: 2 события наступили одновременно или последовательно, затем завершение образования;

- 3 события наступили одновременно.

Таблица 2. Группировка событий в статусы

\begin{tabular}{|c|c|c|c|c|c|c|}
\hline \multirow{3}{*}{$\begin{array}{c}\text { Социоэкономические } \\
\text { события }\end{array}$} & \multicolumn{6}{|c|}{ Демографические события } \\
\hline & \multicolumn{3}{|c|}{ нет детей } & \multicolumn{3}{|c|}{1 ребенок } \\
\hline & одинок & 1 партнер & 1 брак & одинок & 1 партнер & 1 брак \\
\hline \multirow{4}{*}{$\begin{array}{l}\text { Нет события или } \\
1 \text { событие }\end{array}$} & нет событий & & & & & \\
\hline & отделение & & & & & \\
\hline & работа & & & & & \\
\hline & образование & & & & & \\
\hline \multicolumn{7}{|l|}{ Отделение > событие } \\
\hline \multicolumn{7}{|l|}{ Работа > событие } \\
\hline \multicolumn{7}{|l|}{ Образование > событие } \\
\hline \multicolumn{7}{|l|}{2 события одновременно } \\
\hline \multicolumn{7}{|l|}{2 события > отделение } \\
\hline \multicolumn{7}{|l|}{2 события > работа } \\
\hline \multicolumn{7}{|l|}{2 события > образование } \\
\hline \multicolumn{7}{|l|}{3 события одновременно } \\
\hline Цензурирование & & & & & & \\
\hline
\end{tabular}


В таблице 2 отображены не только варианты статусов, но и цветовые коды для каждого из них для упрощения графического восприятия последовательностей. Таблица с указанием аббревиатур для каждого статуса размещена в таблице П-1 Приложения. На рисунке 5 представлены хронограммы для мужчин, которые проходили (слева) и не проходили (справа) службу по призыву. Хронограмма представляет собой распределение частоты появления каждого статуса относительно временных отрезков, в которых наблюдались данные последовательности событий.

В выборке представлены респонденты разных возрастов. Самым молодым на момент опроса всего 19 лет, т.е. мы можем построить биографию всего для 4 лет их жизни. Отрезок жизненного пути, о котором мы не имеем представления, обозначен на хронограммах бордовым градиентом. В терминах продвинутого статистического анализа подобное отсутствие информации о событиях, не успевших произойти в диапазоне наблюдения, называется цензурированием.
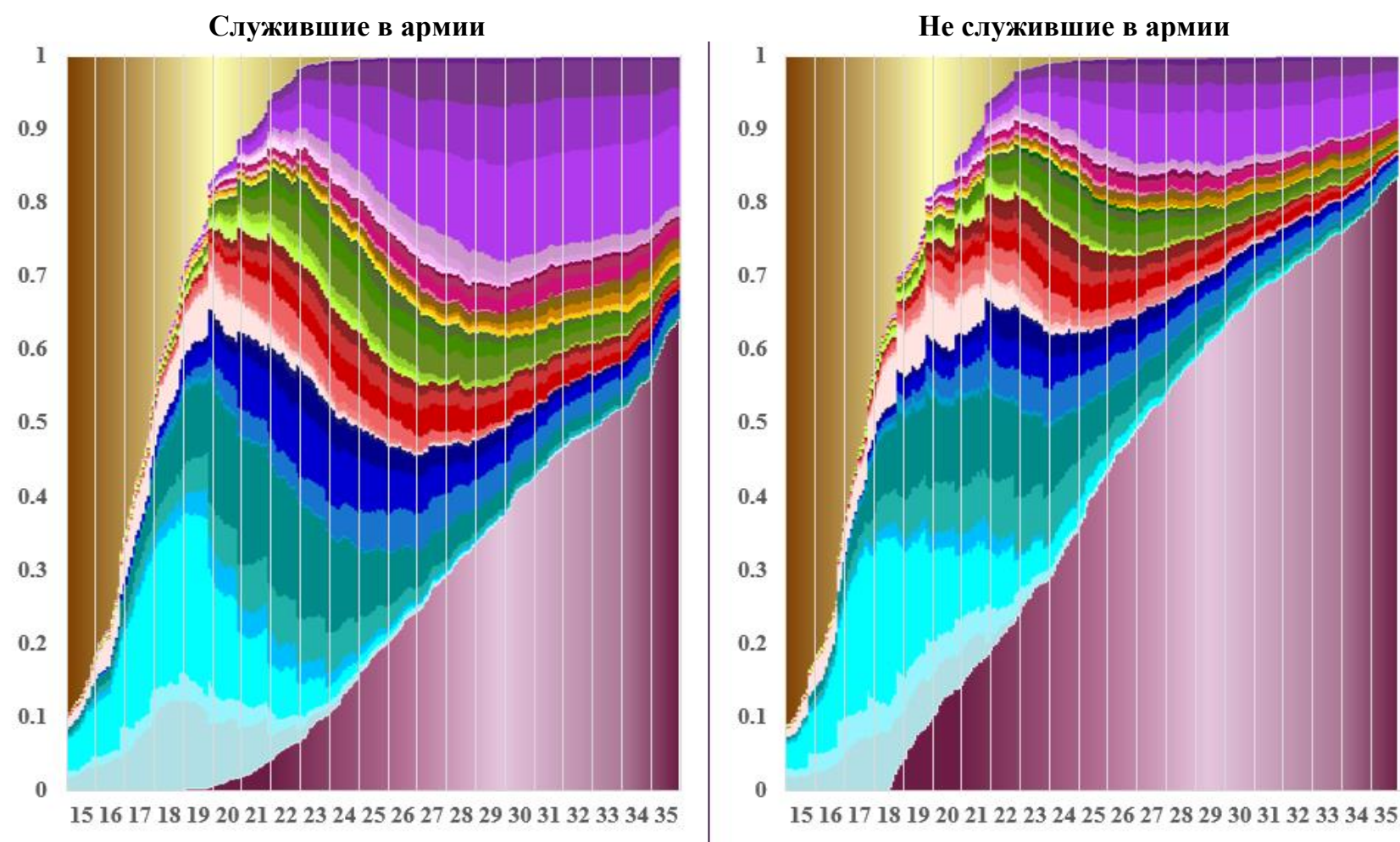

Рисунок 5. Хронограммы наступления стартовых событий для мужчин, служивших и не служивших в армии

Источник: Составлено авторами по данным [ЧСО 2013].

Различия в хронограммах наступления событий показывают особенности жизненного пути в разрезе службы в армии. Если число мужчин, не имеющих социодемографических событий в начале перехода во взрослую жизнь, почти одинаково для обеих категорий, то число цензурированных событий значительно выше у не служивших мужчин. Это говорит о меньшем числе событий, произошедших в их жизни, что может быть обусловлено сравнительной молодостью данной группы мужчин, ведь среди представителей старших поколений доля избежавших срочной службы минимальна, тогда как для молодых людей это становится все более характерным. 
На момент начала наблюдения (15 лет) служившие и не служившие мужчины имеют примерно одинаковый набор событий: несколько событий социоэкономического блока (чаще всего отделение от родителей и наличие образования наивысшего уровня) и совсем небольшая доля демографических событий, а именно партнерств. К возрасту 19 лет (когда отслужившие мужчины находились в армии) среди не отслуживших возрастает доля отделившихся от родителей. Это, скорее всего, связано именно с фактом отбытия на службу, который является причиной для покидания родительского дома минимум на 3 месяца. К концу наблюдения (возраст 35 лет) различия между служившими и не служившими мужчинами становятся особенно заметны: доля состоящих в первом браке, имеющих одного ребенка и какие-то события из социоэкономического блока (фиолетовая палитра) среди служивших составляет порядка $23 \%$, тогда как среди не служивших - менее $10 \%$. Остальные комбинации событий, включающих демографические (красная, розовая, зеленая палитры), также представлены в гораздо большем объеме у мужчин, прошедших срочную службу, чем у не прошедших ее.

В таблице 3 (полная версия - в таблице П-2 Приложения) представлены ранжиры статусов от самого длительного (в месяцах) до самого короткого для всех мужчин, для служивших и для не служивших в армии.

Таблица 3. Ранжирование статусов от самого длительного до самого короткого для всех мужчин, для служивших и для не служивших в армии

\begin{tabular}{|c|c|c|c|c|c|c|}
\hline \multirow[b]{2}{*}{ № пா } & \multicolumn{2}{|c|}{ Bce } & \multicolumn{2}{|c|}{ Служившие в армии } & \multicolumn{2}{|c|}{ Не служившие в армии } \\
\hline & статус & $\begin{array}{c}\text { средняя } \\
\text { длительность, } \\
\text { мес. }\end{array}$ & статус & $\begin{array}{c}\text { средняя } \\
\text { длительность, } \\
\text { мес. }\end{array}$ & статус & $\begin{array}{c}\text { средняя } \\
\text { длительность, } \\
\text { мес. }\end{array}$ \\
\hline 1 & $\mathrm{SCO0}$ & 38,54 & SCO0 & 38,07 & $\mathrm{SCO0}$ & 39,10 \\
\hline 2 & SC0E+ & 14,37 & $\mathrm{M} 1 \mathrm{C} 1++\mathrm{L}$ & 16,88 & SCOE & 13,47 \\
\hline 3 & $\mathrm{SCOE}$ & 13,43 & $\mathrm{SCOE}+$ & 16,08 & SCOE+ & 12,37 \\
\hline 4 & $\mathrm{M} 1 \mathrm{C} 1++\mathrm{L}$ & 13,32 & SCOE & 13,40 & $\mathrm{M} 1 \mathrm{C} 1++\mathrm{L}$ & 9,16 \\
\hline 5 & $\mathrm{M} 1 \mathrm{C} 1++\mathrm{J}$ & 8,05 & $\mathrm{M} 1 \mathrm{C} 1++\mathrm{J}$ & 10,46 & $\mathrm{SCOJ}+$ & 7,57 \\
\hline 6 & $\mathrm{SCOJ}+$ & 6,87 & $\mathrm{SC} 0++\mathrm{J}$ & 8,98 & $\mathrm{SC} 0++\mathrm{L}$ & 5,76 \\
\hline 7 & $\mathrm{SC} 0++\mathrm{J}$ & 6,75 & $\mathrm{M} 1 \mathrm{C} 1++\mathrm{E}$ & 7,25 & $\mathrm{M} 1 \mathrm{C} 1++\mathrm{J}$ & 5,23 \\
\hline 8 & $\mathrm{SC} 0++\mathrm{L}$ & 6,39 & $\mathrm{SC} 0++\mathrm{L}$ & 6,92 & $\mathrm{P} 1 \mathrm{C} 01$ & 4,44 \\
\hline 9 & $\mathrm{M} 1 \mathrm{C} 1++\mathrm{E}$ & 5,70 & SCOL & 6,74 & SCOL & 4,37 \\
\hline 10 & SCOL & 5,65 & SCOJ+ & 6,28 & $\mathrm{SC} 0++\mathrm{J}$ & 4,14 \\
\hline
\end{tabular}

Дольше всего мужчины обеих категорий пребывают в состоянии отсутствия событий любого типа (38 и 39 мес. - более 3 лет). Следующим по длительности (16,9 мес. 1,5 года) у мужчин, служивших в армии, идет статус «в первом браке, с одним ребенком, три сочиоэкономических события, последнее из которых - отделение от родителей», а у мужчин, не служивших в армии, это статус «отсутствие демографических событий, наличие образования наивысшего уровня» (13,5 мес. - 1 год и 1,5 мес.). Третьим для служивших (16 мес. - 1 год и 4 мес.) и не служивших (12,3 мес. - 1 год) следует статус «отсутствие демографических событий, два сочиоэкономических события, последнее из которых - наличие образования наивысшего уровня». Четвертое наиболее длительное событие для служивших (13,4 мес.- 1 год и 1 мес.) - «отсутствие демографических событий, наличие образования наивысшего уровня», для не служивших (9 мес.) - «в первом браке, с одним ребенком, три события, последнее из которых-отделение от родителей». 
Как видно из этих ранжиров, мужчины, служившие в армии, пребывают во всех статусах дольше, чем не служившие. Это говорит о том, что они раньше открывают свои траектории. Наиболее продолжительным для служивших мужчин является самый насыщенный статус, в котором есть и демографическая, и социоэкономическая составляющие, тогда как для не служивших мужчин характернее всего отсутствие демографических событий и наличие образования. Статусы более высокого ранга очень схожи и различаются в основном позицией в списке и длительностью.

В таблицах 4 и 5 (полные версии - в таблицах П-3 и П-4 Приложения соответственно) представлены самые частые подпоследовательности событий для служивших и не служивших мужчин. В нашей работе под частыми понимаются такие подпоследовательности, уровень поддержки которых (доля мужчин из численности соответствующей категории) превышает 9\%. Подпоследовательности могут состоять как из одного статуса, так и из нескольких.

Таблица 4. Ранжирование подпоследовательностей по частоте встречаемости у респондентов, служивших в армии

\begin{tabular}{|c|c|c|c|}
\hline № & Последовательность & $\begin{array}{l}\text { Доля в числе } \\
\text { служивших }\end{array}$ & Чел. \\
\hline 1 & (SC00) & 0,905 & 1005 \\
\hline 2 & $(\mathrm{SC} 00)-(\mathrm{SCO}>\mathrm{SC} 0 \mathrm{E})$ & 0,436 & 484 \\
\hline 3 & $(\mathrm{SC} 00>\mathrm{SC} 0 \mathrm{E})$ & 0,436 & 484 \\
\hline 4 & $(\mathrm{SCOE}>\mathrm{SCOE}+)$ & 0,389 & 432 \\
\hline 5 & $(\mathrm{SC} 00)-(\mathrm{SC} 0 \mathrm{E}>\mathrm{SCOE}+)$ & 0,356 & 395 \\
\hline 6 & $(\mathrm{SC} 00)-(\mathrm{SC} 00>\mathrm{SC} 0 \mathrm{E})-(\mathrm{SC} 0 \mathrm{E}>\mathrm{SC} 0 \mathrm{E}+)$ & 0,350 & 389 \\
\hline 7 & $(\mathrm{SCO}>\mathrm{SCOE})-(\mathrm{SCOE}>\mathrm{SCOE}+)$ & 0,350 & 389 \\
\hline 8 & $(\mathrm{SC} 00>\mathrm{SCOL})$ & 0,194 & 216 \\
\hline 9 & $(\mathrm{SC} 00)-(\mathrm{SCO}>\mathrm{SCOL})$ & 0,194 & 215 \\
\hline 10 & $(\mathrm{SCOL}>\mathrm{SCOL}+)$ & 0,166 & 184 \\
\hline 11 & $(\mathrm{SC} 00)-(\mathrm{SCO}>\mathrm{SC} 0 \mathrm{~J})$ & 0,163 & 181 \\
\hline 12 & $(\mathrm{SCO0}>\mathrm{SCOJ})$ & 0,163 & 181 \\
\hline 13 & $(\mathrm{M} 1 \mathrm{C} 0++\mathrm{L}>\mathrm{M} 1 \mathrm{C} 1++\mathrm{L})$ & 0,157 & 174 \\
\hline 14 & $(\mathrm{SCO0})-(\mathrm{SC} 00>\mathrm{SCOL})-(\mathrm{SCOL}>\mathrm{SCOL}+)$ & 0,150 & 167 \\
\hline 15 & $(\mathrm{SCO0})-(\mathrm{SCOL}>\mathrm{SCOL}+)$ & 0,150 & 167 \\
\hline 16 & $(\mathrm{SCO}>\mathrm{SC} 0 \mathrm{~L})-(\mathrm{SCOL}>\mathrm{SCOL}+)$ & 0,150 & 167 \\
\hline 17 & $(\mathrm{SC00})-(\mathrm{M} 1 \mathrm{C} 0++\mathrm{L}>\mathrm{M} 1 \mathrm{C} 1++\mathrm{L})$ & 0,143 & 159 \\
\hline 18 & $(\mathrm{SCOJ}>\mathrm{SCOJ}+)$ & 0,134 & 149 \\
\hline 19 & $(\mathrm{SC} 00)-(\mathrm{SC} 00>\mathrm{SC} 0 \mathrm{~J})-(\mathrm{SCOJ}>\mathrm{SC} 0 \mathrm{~J}+)$ & 0,125 & 139 \\
\hline 20 & $(\mathrm{SCO0})-(\mathrm{SCOJ}>\mathrm{SCOJ}+)$ & 0,125 & 139 \\
\hline 21 & $(\mathrm{SCO0}>\mathrm{SC} 0 \mathrm{~J})-(\mathrm{SCOJ}>\mathrm{SCOJ}+)$ & 0,125 & 139 \\
\hline 22 & $(\mathrm{SCOE}+>\mathrm{P} 1 \mathrm{COE}+)$ & 0,098 & 109 \\
\hline 23 & $(\mathrm{SCO0}>\mathrm{P} 1 \mathrm{C01})$ & 0,096 & 107 \\
\hline 24 & $(\mathrm{SC} 0 \mathrm{E}+>\mathrm{SC} 0++\mathrm{L})$ & 0,095 & 105 \\
\hline 25 & $(\mathrm{SC00})-(\mathrm{SC00}>\mathrm{P} 1 \mathrm{C} 01)$ & 0,092 & 102 \\
\hline 26 & $(\mathrm{SCOE}>\mathrm{SC} 0 \mathrm{E}+)-(\mathrm{SCOE}+>\mathrm{SC} 0++\mathrm{L})$ & 0,092 & 102 \\
\hline
\end{tabular}

Больше всего служивших мужчин состоит в статусе «отсутствие событий»: 1005 из 1111 человека. Это говорит о том, что только 10\% мужчин имели какие-то события к моменту начала наблюдения (15-летию). 44\% из тех, кто служил, имеют подпоследовательность «отсутствие событий, затем - наличие образования», 35\% из них после образования совершили еще одно социоэкономическое событие (трудоустройство 
или отделение от родителей). У 19\% мужчин первым событием было отделение от родителей. 17\% из этого числа далее совершили еще одно социоэкономическое событие. У 16\% первым событием было трудоустройство, в 13\% случаев дополненное еще одним социоэкономическим событием. Далее у отслуживших мужчин начинают встречаться подпоследовательности с демографическими событиями. $16 \%$ мужчин имеют подпоследовательность «в первом браке, без детей, три социоэкономических события, последнее из которых - отделение от родителей, затем - то же, но с одним ребенком». 10\% сначала имеют только образование и еще одно социоэкономическое событие, а затем они вступают в первое партнерство. Столько же респондентов сначала не имеют ни одного события, а затем вступают в первое партнерство и совершают одно, либо ни одного социоэкономического события. Все остальные подпоследовательности у данной категории мужчин имеют уровень поддержки менее 100 человек. То есть всего для служивших мужчин найдено 26 подпоследовательностей, встретившихся более чем у 9\% подвыборки.

У не служивших мужчин выявлено 22 подпоследовательности, встретившихся более чем у $9 \%$ подвыборки (таблица 5).

Таблица 5. Ранжирование подпоследовательностей по частоте встречаемости у респондентов, не служивших в армии

\begin{tabular}{|c|c|c|c|}
\hline № & Последовательность & $\begin{array}{l}\text { Доля в числе не } \\
\text { служивших }\end{array}$ & Чел. \\
\hline 1 & $(\mathrm{SC} 00)$ & 0,924 & 879 \\
\hline 2 & $(\mathrm{SC} 00>\mathrm{SCOE})$ & 0,441 & 419 \\
\hline 3 & $(\mathrm{SC} 00)-(\mathrm{SCOO}>\mathrm{SCOE})$ & 0,440 & 418 \\
\hline 4 & $(\mathrm{SCOE}>\mathrm{SCOE}+)$ & 0,306 & 291 \\
\hline 5 & $(\mathrm{SC} 00)-(\mathrm{SC} 0 \mathrm{E}>\mathrm{SCOE}+)$ & 0,284 & 270 \\
\hline 6 & $(\mathrm{SC} 00>\mathrm{SC} 0 \mathrm{E})-(\mathrm{SCOE}>\mathrm{SCOE}+)$ & 0,279 & 265 \\
\hline 7 & $(\mathrm{SC} 00)-(\mathrm{SC} 00>\mathrm{SC} 0 \mathrm{E})-(\mathrm{SCOE}>\mathrm{SCOE}+)$ & 0,278 & 264 \\
\hline 8 & $(\mathrm{SC} 00)-(\mathrm{SC} 00>\mathrm{SCOJ})$ & 0,205 & 195 \\
\hline 9 & $(\mathrm{SC} 00>\mathrm{SCOJ})$ & 0,205 & 195 \\
\hline 10 & $(\mathrm{SC} 0 \mathrm{~J}>\mathrm{SCOJ}+)$ & 0,182 & 173 \\
\hline 11 & $(\mathrm{SC} 00)-(\mathrm{SCOJ}>\mathrm{SC} 0 \mathrm{~J}+)$ & 0,171 & 163 \\
\hline 12 & $(\mathrm{SC} 00)-(\mathrm{SC} 00>\mathrm{SC} 0 \mathrm{~J})-(\mathrm{SC} 0 \mathrm{~J}>\mathrm{SCOJ}+)$ & 0,170 & 162 \\
\hline 13 & $(\mathrm{SC} 00>\mathrm{SC} 0 \mathrm{~J})-(\mathrm{SCOJ}>\mathrm{SCOJ}+)$ & 0,170 & 162 \\
\hline 14 & $(\mathrm{SC} 00)-(\mathrm{SC} 00>\mathrm{SCOL})$ & 0,135 & 128 \\
\hline 15 & $(\mathrm{SC} 00>\mathrm{SCOL})$ & 0,135 & 128 \\
\hline 16 & $(\mathrm{SCO0}>\mathrm{P1C01})$ & 0,129 & 123 \\
\hline 17 & $(\mathrm{SC00})-(\mathrm{SCO0}>\mathrm{P} 1 \mathrm{C} 01)$ & 0,127 & 121 \\
\hline 18 & $(\mathrm{SCOL}>\mathrm{SCOL}+)$ & 0,111 & 106 \\
\hline 19 & $(\mathrm{SCO0})-(\mathrm{SCOL}>\mathrm{SCOL}+)$ & 0,102 & 97 \\
\hline 20 & $(\mathrm{SC} 00)-(\mathrm{SC} 00>\mathrm{SCOL})-(\mathrm{SCOL}>\mathrm{SCOL}+)$ & 0,101 & 96 \\
\hline 21 & $(\mathrm{SC} 00>\mathrm{SCOL})-(\mathrm{SCOL}>\mathrm{SCOL}+)$ & 0,101 & 96 \\
\hline 22 & $(\mathrm{M} 1 \mathrm{C} 0++\mathrm{L}>\mathrm{M} 1 \mathrm{C} 1++\mathrm{L})$ & 0,094 & 89 \\
\hline
\end{tabular}

Примечание: Подпоследовательности, содержащие демографические события, обозначены жирным шрифтом.

Наиболее популярная подпоследовательность также состоит из одного статуса «отсутствие событий» (92\%; 879 мужчин из 951). Следующая по популярности подпоследовательность тоже совпадает у служивших и не служивших в армии: это «отсутствие событий, затем - наличие образования» (44\%), к ней в 30\% случаев добавляется еще одно социоэкономическое событие. А дальше ситуация меняется: третьим по популярности у не служивших является подпоследовательность «отсутствие событий, 
затем трудоустройство» (20\%); для $18 \%$ через какое-то время добавляется еще одно социоэкономическое событие. Четвертым по уровню поддержки следует отделение от родителей (13\%), в 11\% случаев дополненное еще одним социоэкономическим событием. На этом этапе у не служивших мужчин также начинают появляться демографические события, но уровень поддержки значительно меньше и лидирует не брак, а партнерство: у 13\% мужчин из подвыборки встречается подпоследовательность «отсутствие событий, затем - первое партнерство без ребенка», у 9,4\% - «первый брак без ребенка, три социоэкономических события, последнее из которых - отделение от родителей, затем появление ребенка».

Таким образом, каждый девятый мужчина в выборке (вне зависимости от службы в армии) в течение какого-то времени не имел ни одного социодемографического события. $44 \%$ мужчин в определенный момент времени завершили получение образования. 19\% служивших и 13\% не служивших отделились от родителей; 16 и 18\% соответственно трудоустроились; 16 и 9\% - женились, завели ребенка и совершили все три статусных перехода в социоэкономической сфере, последним из которых было отделение от родителей; 10 и 13\% - начали жить в партнерстве. В целом последовательности, содержащие разные демографические события, чаще встречаются у мужчин, прошедших армейскую службу.

Рассмотрим далее хронограммы последовательностей событий для каждой когорты в разрезе службы в армии (рисунок 6).

Прежде всего стоит обратить внимание на количество служивших и не служивших в армии мужчин: если в самом старшем поколении число служивших более чем в 2 раза превышало число не служивших, то для поколения 1990-1994 г.р. наблюдается диаметрально противоположная ситуация. Однако, несмотря на разную наполненность категорий, цензурирований стабильно больше у тех, кто не проходил срочную службу. То есть армия, какая бы доля поколений в нее не призывалась, способствует более интенсивному наполнению жизненного пути событиями.

Сильнее всего различаются хронограммы для самых старших и самых молодых поколений. Мужчины 1970-1974 г.р., служившие в советское время, раньше завершают получение образования (останавливаясь на более низкой ступени, чем не служившие), раньше отделяются от родителей (что, скорее всего, обусловлено службой в армии). К 17 годам не служившие мужчины чаще служивших состоят в партнерствах без детей. К 35 годам среди тех, кто прошел срочную службу, больше женатых мужчин с детьми (фиолетовая палитра; более 60\%), чем среди тех, кто ее не прошел (более 50\%). В целом у служивших больше последовательностей, включающих демографические события (все палитры, кроме синей). 


\section{Служившие в армии}

261 наблюдение

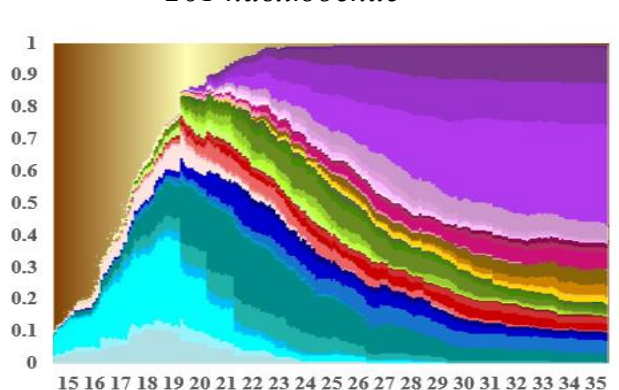

1970 - 1974 г.p.

\section{Не служившие в армии}

250 наблюдений

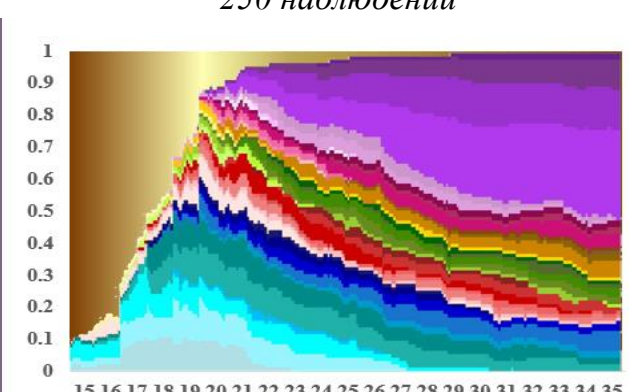

1975 - 1979 г.p.

279 наблюдений
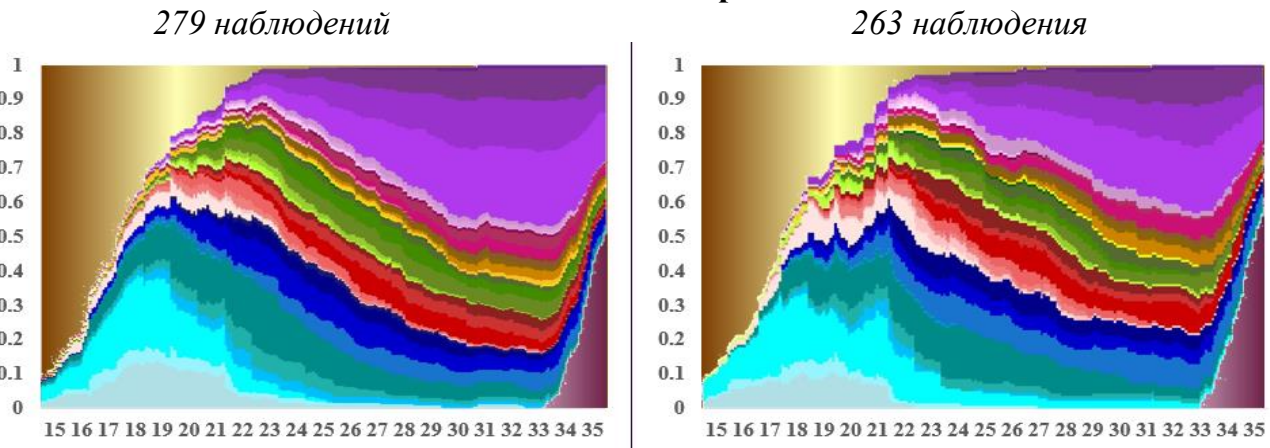

1980 - 1984 г.p.

214 наблюдений
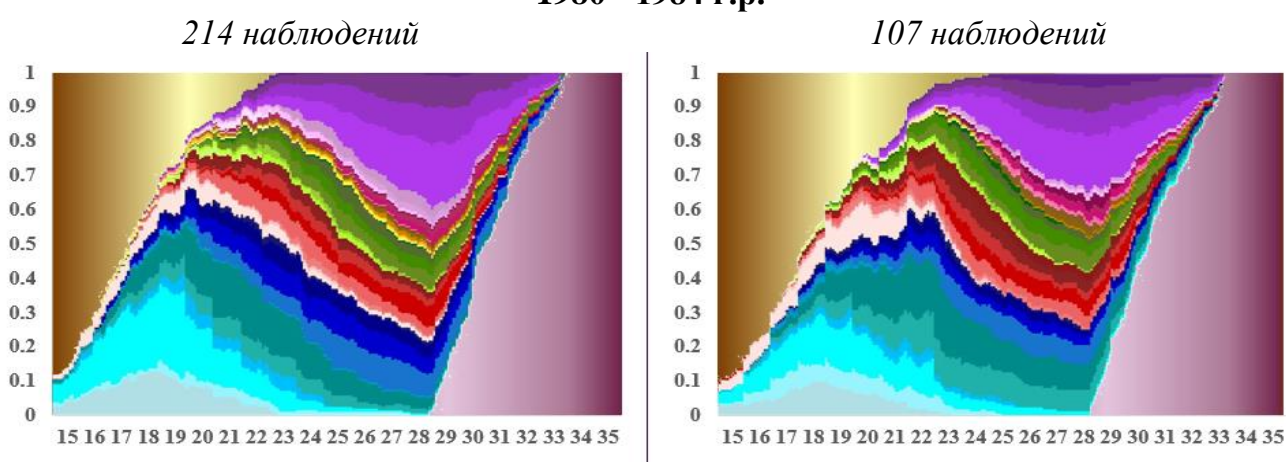

Служившие в армии

250 наблюдений

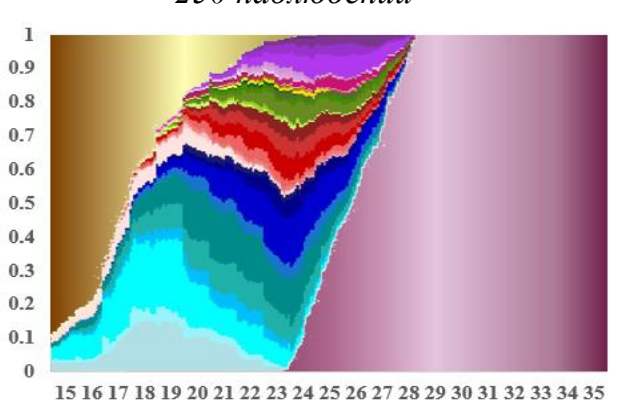

1990 - 1994 г.p.
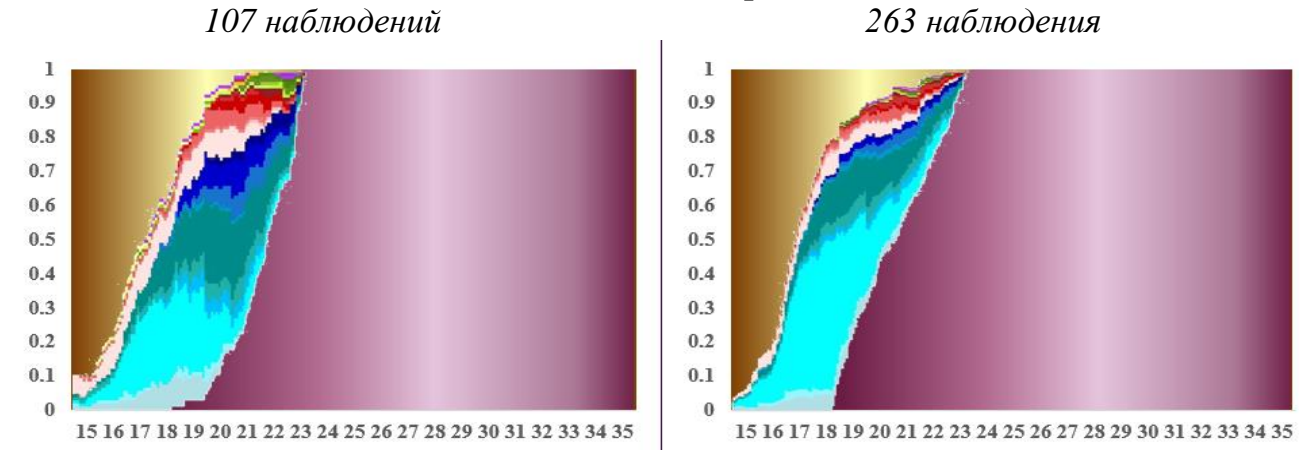

Рисунок 6. Хронограммы наступления стартовых событий для служивших и не служивших в армии мужчин разных поколений Источник: Составлено авторами по данным [ЧСО 2013]. 
У мужчин, родившихся после 1990 г., еще очень много цензурирований, так как самым молодым респондентам на момент опроса (2013 г.) всего 19 лет, самым старшим из этого поколения - 23 года. Тем не менее различия между категориями просматриваются довольно четко: у мужчин, служивших в армии, больше и социоэкономических, и демографических событий, нежели у тех, кто не служил. У них больше отделений от родителей, что связано непосредственно со службой в армии. Они быстрее и интенсивнее совершают все социоэкономические события (синие цвета), вступают в партнерства (красная палитра), браки (зеленые цвета) и обзаводятся детьми (желтые, розовые, фиолетовые цвета).

Представленные хронограммы как в разрезе поколений, так и в целом для всех когорт, являются подтверждением Гипотезы 2, что демографические события у тех, кто прошел службу в армии, будут наступать раньше и интенсивнее, чем у тех, кто не служил.

\section{ЗАКЛЮЧЕНИЕ}

Проведенное исследование предоставляет целую серию эмпирических доказательств наличия различий в жизненных путях мужчин, служивших и не служивших в армии.

В советское время на срочную службу призывалось 80-90\% 18-летних мужчин (рисунок 1), а в современной России эта доля опускается ниже порога в 50\%. Причина превышения доли «белобилетников» над служившими кроется в смене механизма отбора на срочную службу. Построенные социодемографические «портреты» показывают, что для мужчин, служивших в советское время, отсутствовали различия в характеристиках на момент 15-летия и на дату опроса (2013 г.). Единственной переменной, по которой есть незначительные различия, является инвалидность, что подтверждает селективность в советское время исключительно по состоянию здоровья. Характеристики респондентов, служивших в постсоветский период, говорят о том, что возможность избежать службы в армии связана с социальными связями родителей. Мужчины, получившие подобную отсрочку, позднее, чем их отслужившие сверстники, становятся самостоятельными, но больше вкладываются в развитие своих профессиональных навыков.

Анализ последовательностей показал, что мужчины, прошедшие срочную службу, совершают социоэкономические и демографические события раньше и интенсивнее. Сильнее всего различаются хронограммы для самых старших и самых молодых поколений. Мужчины 1970-1974 г.р., служившие в советское время, раньше завершают получение образования (останавливаясь на более низкой ступени, чем не служившие), раньше отделяются от родителей. К 35 годам среди тех, кто прошел срочную службу, больше женатых мужчин с детьми, чем среди тех, кто ее не прошел. У мужчин, родившихся после 1990 г., еще очень много цензурирований, тем не менее они быстрее и интенсивнее совершают все социоэкономические события, вступают в партнерства, браки и обзаводятся детьми.

Принимая во внимание, что служившие мужчины чаще всего являются представителями старших поколений, а не служившие - младших, мы не делаем однозначных выводов о влиянии службы в армии на жизненные события, так как имеем 
дело с межпоколенными трансформациями социодемографического поведения и с разной подверженностью поколений цензурированию (у молодых меньше событий в силу более юного возраста). Тем не менее можно сделать однозначный вывод, что имеющие опыт срочной службы формируют свой жизненный путь несколько иначе, чем те, кто не проходил эту «школу жизни». Результатом чего является этот феномен (межпоколенных трансформаций, изменения отношения к армии, селекции при наборе на службу или эффектом самой службы) - вопрос, требующий дополнительного изучения с привлечением продвинутых методов не только анализа, но и сбора информации (когортные, лонгитюдные исследования с тщательно проработанным набором индикаторов).

\section{ЛИТЕРАТУРА}

Артамонова А.В., Е.С. Митрофанова (2016). Сожительства в России: промежуточное звено или легитимный институт/Мониторинг общественного мнения: Экономические и социальные перемены. № 1: 126-145.

Бочавер А.А. (2008). Исследования жизненного пути человека в современной зарубежной психологии // Психологический журнал. №5: 54-62.

Градосельский В.В. (2005). Комплектование Вооруженных Сил СССР в 1970-1980-е годы // Военно-исторический журнал. №.9: 18-21.

Гурко Т. (2001). Трансформация брачно-семейных отношений // Россия: трансформирующееся общество / Под редакцией В.А. Ядова. М.: КАНОН-пресс-Ц.: 272-283.

Данилова Н.Ю. (2005). Срочники, пиджаки, профессионалы: разные мужественности участников постсоветских войн // Журнал социологии и социальной антропологии. T.8. № 2: 110-126.

Денисенко М.Б., Ж.-П. Далла Зуанна (2001). Сексуальное поведение российской молодежи // Социологические исследования. № 2: 83-87.

Долгова А.А., Е.С. Митрофанова (2015). Отделение от родительской семьи в России: межпоколенческий аспект // Экономическая социология. Т.16. № 5: 46-76.

Ежов О.Н. (2005). Парадигма жизненного пути в зарубежной социологии // Журнал социологии и социальной антропологии. Т.8. № 3: 22-33

Захаров С.В. (2007). Демографические обследования населения: прошлое, настоящее, будущее // Родители и дети, мужчины и женщины в семье и обществе / Под науч. ред. Т.М. Малевой, О.В. Синявской. М.: НИСП: 640.

Кон И.С. (1999). Социологическая психология. Воронеж: МОДЭК: 254-270.

Магун В. (2009). Нормативные взгляды на семью у россиян и французов // Родители и дети, мужчины и женщины в семье и обществе. М.: НИСП: 139-162.

Малева Т.М. и др. (2014). Разработка методологии и проведение первой пилотной волны регулярного общенационального репрезентативного обследования населения по изучению демографического, социального и экономического поведения, включая пенсионное поведение. М.: РАНХиГС.

Митрофанова Е.С. (2010). Семья и брак, матримониальное, репродуктивное и сексуальное поведение в крестьянской, советской и современной России // Демоскоп Weekly. № 
423 - 424. URL: http://demoscope.ru/weekly/2010/0423/student01.php (дата обращения: 20.02.2015).

Михель Д. (2001). Мужчины, мальчики и поле боя // Гендерные исследования. Т.6: 133149.

Основной Закон (Конституция) Союза Советских Социалистических Республик (1940) // Конституции и конституционные акты СССР (1922-1936). Сборник документов / Под ред. И.П. Трайнина. М.

Попова Д.О. (2009). Трансформация семейных ценностей и второй демографический переход в России: кто в авангарде? // Родители и дети, мужчины и женщины в семье и обществе / Под науч. ред. С.В. Захарова, Т.М. Малевой, О.В. Синявской. М.: НИСП: 336.

РБК (2015). 25 апреля. URL: http://www.rbc.ru/rbcfreenews/553b923f9a79477833fc113b (дата обращения: 24.02.2015).

РМЭЗ (2013). Российский мониторинг экономического положения и здоровья населения НИУ-ВШЭ (22-я волна), проводимый НИУ «Высшая школа экономики» и ЗАО «Демоскоп» при участии Центра народонаселения Университета Северной Каролины в Чапел Хилле и Института социологии PAH. URL: http://www.hse.ru/rlms (дата обращения: 20.02.2015).

Рождественская Е.Ю. (2012). Биографический метод в социологии. М.: Изд. дом Высшей школы экономики: 381.

Смирнов А.И. (2009). Служба в армии потерянное время // Социологические исследования. Т.12: 100-108.

Суханова М. (2014). Отношение юношей к службе в армии // Материалы IX международной научно-практической конференции преподавателей и студентов «Человек в XXI веке». Обнинск: 78-79.

Форбс (2011). 25 октября. URL: http://www.forbes.ru/news/76858-medvedev-cherez-5-7-letdolya-prizyvnikov-v-armii-rf-sokratitsya-do-10-20 (дата обращения: 24.02.2015).

ЧСО (2013). Обследование демографического, социального и экономического поведения населения Российской Федерации «Человек, семья, общество» (1-я волна), проводимое Институтом социального анализа и прогнозирования РАНХиГС.

Abbott A. (1995). Sequence Analysis: new methods for old ideas // Annual Review of Sociology. V.21. №1: 93-113.

Billari F., R. Piccarreta (2005). Analyzing demographic life courses through Sequence Analysis // Mathematical Population Studies. V.12. №2: 81-106.

Billari F.C. (2001). Sequence Analysis in demographic research // Canadian Studies in Population. V.28. №2: 439-458.

Britton P., P. Ouimette, R. Bossarte (2012). The effect of depression on the association between military service and life satisfaction // Quality of Life Research. V.21. №10: 1857-1862.

Elder J.G.H. (1987). War mobilization and the life course: A cohort of World War II veterans // Sociological Forum 2: Kluwer Academic Publishers: 449-472.

Forrest A. (1989). Conscripts and deserters: The army and French society during the Revolution and Empire. New York: Oxford University Press. First edition: 304.

Friedman M. (1967). Why not a volunteer army? // New Individualist Review. V.4. №4: 3-6. 
Jennings J.A., A.R. Sullivan, J.D. Hacker (2012). Intergenerational transmission of reproductive behavior during the demographic transition // Journal of Interdisciplinary History. V.42. №4: 543-569.

Lesthaeghe R. (1995). The second demographic transition in Western countries: An interpretation // Gender and family change in industrialized countries. Oxford: Clarendon Press: 17-62.

MacLean A., G.H. Elder (2007). Military service in the life course // Annual Review of Sociology. V.33. №1: 175-196.

Potârcă G., M. Mills, L. Lesnard (2013). Family formation trajectories in Romania, the Russian Federation and France: Towards the second demographic transition? // European Journal of Population. V.29. №1: 69-101.

Ritschard G., M. Oris (2005). Life course data in demography and social sciences: Statistical and data-mining approaches // Advances in Life Course Research. V.10: 283-314.

Sampson R.J., J.H. Laub (1996). Socioeconomic achievement in the life course of disadvantaged men: Military service as a turning point, circa 1940-1965 // American Sociological Review. V.61. №3: 347-367.

Shearer D. (1998). Private armies and military intervention. London: Adelphi Paper: 316.

Van de Kaa D.J. (1987). Europe's second demographic transition // Population Bulletin. V.42: 3-57.

Van Schellen M., R. Apel, P. Nieuwbeerta (2012). "Because you're mine, I walk the line"? Marriage, spousal criminality, and criminal offending over the life course // Journal of Quantitative Criminology. V.28. №4: 701-723 


\section{THE SEQUENCE OF LIFE EVENTS OF RUSSIAN MEN SERVING AND NOT SERVING IN THE MILITARY*}

\section{EKATERINA MITROFANOVA}

Ekaterina Mitrofanova. NATIONAL ReSEARCH University Higher SchOOl of ECONOMics (Russia). E-MAIL: emitrofanova@hse.ru.

\section{ALYONA ARTAMONOVA}

Alyona Artamonova. National Research University Higher School of Economics (Russia).

E-mail: aartamonova@hse.ru

DATE RECEIVED: September 2015 .

Using two representative Russian surveys - "Person, Family, Society" (used for building research models) and "Russian monitoring of the economic condition and health of the population" (for auxiliary, descriptive analysis) - we analyzed the differences in the life courses of Russian men who served and did not serve in the army. For these two groups of men, we compared the ages and sequences of the most important first events (separation from the parental home, first job, obtaining an education, first cohabitation, first marriage, and first child). We constructed socio-demographic "portraits" for these men at the age of 15 and at the moment of the survey (2013).

Our results revealed that those men who served in the military have more socio-economic and demographic events than those who avoided military service: men with military experience start adult life earlier and more intensively. The mechanism of selecting men for military service has changed since the 1990s. Men who serve are mainly children of parents without higher education and not occupying senior positions in the period of their children's socialization. After completing] military service, men often work and live separately, while those who did not serve in the army study and live with their parents.

Key words: army, conscription, serving in the military, demographic behavior, job, education, separation from parental home, marriage, cohabitation, Russia, life course, sequence analysis.

\footnotetext{
* THIS ARTICLE WAS PREPARED WITHIN THE FRAMEWORK OF THE ACADEMIC FUND PROGRAM AT THE NATIONAL RESEARCH UNIVERSITY HIGHER SCHOOL OF ECONOMICS (HSE) IN 2016 (GRANT № 16-05-0011 “DEVELOPMENT AND TESTING OF DEMOGRAPHIC SEQUENCE ANALYSIS AND MINING TECHNIQUES”) AND SUPPORTED WITHIN THE FRAMEWORK OF A SUBSIDY GRANTED TO THE HSE BY THE GOVERNMENT OF THE RUSSIAN FEDERATION FOR THE IMPLEMENTATION OF THE GLOBAL COMPETITIVENESS PROGRAM.
}

\section{REFERENCES}

Abbott A. (1995). Sequence Analysis: new methods for old ideas // Annual Review of Sociology. T.21. №1: 93-113.

Artamonova A., E. Mitrofanova (2016). Sozhitelstva v Rossii: promezhutochnoe zveno ili legitimniy institut [Cohabitation in Russia: "trial" union or an independent social institution] // Monitoring obshestvennogo mneniya: economicheskie i socialnie peremeny [Monitoring of public opinion: economic and social changes]. № 1: 126-145.

Billari F., R. Piccarreta (2005). Analyzing demographic life courses through Sequence Analysis // Mathematical Population Studies. V.12. №2: 81-106.

Billari F.C. (2001). Sequence Analysis in demographic research // Canadian Studies in Population. V.28. №2: 439-458.

Bochaver A. (2008). Issledovaniya zhiznennogo puti cheloveka v sovremennoy zarubezhnoy psihologii [Investigations of men's life course in contemporary foreign psychology] // Psihologicheskiy zhurnal [Psychological journal]. №5: 54-62. 
Britton P., P. Ouimette, R. Bossarte (2012). The effect of depression on the association between military service and life satisfaction // Quality of Life Research. V.21. №10: 1857-1862.

ChSO [MFO] (2013). Obsledovaniye demokraticheskogo, sotsial'nogo i ekonomicheskogo povedeniya naseleniya Rossiyskoy Federatsii «Chelovek, sem'ya, obshchestvo» (1-ya volna), provodimoye Institutom sotsial'nogo analiza i prognozirovaniya RANKhiGS [A survey of the demographic, social and economic behavior of the population of the Russian Federation «Man, family, society» (1st wave), conducted by the Institute for Social Analysis and Forecasting, RANEPA].

Danilova N. (2005). Srochniki, pidzhaki, professionaly: raznye muzhestvennosti uchastnikov postsovetskih voin [Different masculinities of post-Soviet wars participants] // Zhurnal sociologii i socialnoy antropologii [Journal of Sociology and Social Anthropology]. V.8. №2: $110-126$.

Denisenko M., Zh.-P. Dalla Zuanna (2001). Seksualnoe povedenie rossiyskoy molodezhi [Sexual behavior of Russian youth] // Sociologicheskie issledovaniya [Sociological studies]. №2: 8387.

DolgovaA., E. Mitrofanova (2015). Otdelenie ot roditel'skoy sem'i v Rossii: mezhpokolencheskiy aspekt [[Leaving the parental home in Russia: Intergenerational aspects] // Economicheskaya sociologiya [Economic Sociology]. V.16. №5.

Elder J.G.H. (1987). War mobilization and the life course: A cohort of World War II veterans // Sociological Forum 2: Kluwer Academic Publishers: 449-472.

Ezhov O. (2005). Paradigma zhiznennogo puti v zarubezhnoy sociologii [The paradigm of the life course in the foreign sociology] // Zhurnal sociologii i social'noy antropologii [Journal of Sociology and Social Anthropology]. V.8. №3.

Forbes (2011). October 25. URL: http://www.forbes.ru/news/76858-medvedev-cherez-5-7-letdolya-prizyvnikov-v-armii-rf-sokratitsya-do-10-20 (data accessed: 24.02.2015).

Forrest A. (1989). Conscripts and deserters: The army and French society during the Revolution and Empire. New York: Oxford University Press. First edition: 304.

Friedman M. (1967). Why not a volunteer army? // New Individualist Review. V.4. №4: 3-6.

Gradoselskiy V. (2005). Komplektovanie vooruzhennih sil SSSR v 1970 - 1980-e gody [Completion of Soviet Union armed forces in 1970-1980] // Voenno-istoricheskiy zhurnal [War-historical Journal]. №9: 18-21.

Gurko T. (2001). Transformaciya brachno-semeinyh otnosheniy [The transformation of marital and family relationships] // Russia: transformiruyusheesya obshestvo / V. Yadov, ed. Moscow: KANON-press-C: 272-283.

Jennings J.A., A.R. Sullivan, J.D. Hacker (2012). Intergenerational transmission of reproductive behavior during the demographic transition // Journal of Interdisciplinary History. V.42. №4: 543-569.

Kon I. (1999). Sociologicheskaya psihologiya [Sociological psycology] // Voronezh: MODEK: 254-270.

Lesthaeghe R. (1995). The second demographic transition in Western countries: An interpretation // Gender and family change in industrialized countries. Oxford: Clarendon Press: $17-62$.

MacLean A., G.H. Elder (2007). Military service in the life course // Annual Review of Sociology. V.33. №1: 175-196. 
Magun V. (2009). Normativnye vzglyady na semyu u rossiyan i francusov [Normative views on the family among Russian and French people] // Roditeli i deti, muzhchiny i zhenshiny v sem'ei obshestve [Parents and children, men and women in family and society]. M.: NISP.139-162.

Maleva T. et al. (2014). Razrabotka metodologii i provedeniye pervoy pilotnoy volny regulyarnogo obshenacional'nogo reprezentativnogo obsledovaniya naseleniya po izucheniyu demograficheskogo, social'nogo i ekonomicheskogo povedeniya, vkluchaya pensionnoe povedenie [Development of methodology and holding of the first pilot wave of regular national representative survey of population on the demographic, social and economic behavior, including retirement behavior]. M.: RANEPA.

Mihel' D. (2001). Muzhchiny, mal'chiki v pole boya [Men, boys on the battlefield] // Gendernye Issledovaniya [Gender Studies]. V.6: 133-149.

Mitrofanova E. (2010). Semya i brak, matrimonial'noe, reproduktivnoe i seksual'noe povedenie v krestyanskoy, sovetskoy i sovremennoy Rossii [Family and marriage, matrimonial, reproductive and sexual behavior in peasant, Soviet, and contemporary Russia] // Demoscope Weekly. №423 - 424. URL: http://demoscope.ru/weekly/2010/0423/student01.php (data accessed: 20.02.2015).

Osnovnoy Zakon (Konstituziya) SSSR (1940) [The Basic Law (Constitution) of the USSR (1940)] // Konstituzii i konstituzionnye akty SSSR (1922-1936). Sbornik dokumentov [Constitutions and constitutional acts of the USSR (1922-1936). Collection of documents] / I.P. Traynina, ed. M.

Popov D. (2009). Transformaciya semeinyh cennostey i vtoroy demograficheskiy perehod v rossii: kto $\mathrm{v}$ avangarde? [Transformation of family values and second demographic transition: who is in vanguard?] // Roditeli i deti, muzhchiny i zhenshiny v sem'e i obshestve [Parents and children, men and women in family and society] / S.Zaharov, T. Maleva, O. Sinyavskaya, eds. M.: NISP: 336.

Potârcă G., M. Mills, L. Lesnard (2013). Family formation trajectories in Romania, the Russian Federation and France: Towards the second demographic transition? // European Journal of Population. V.29. №1: 69-101.

RBK (2015). April 25. URL: http://www.rbc.ru/rbcfreenews/553b923f9a79477833fc113b (data accessed: 24.02.2015).

Ritschard G., M. Oris (2005). Life course data in demography and social sciences: Statistical and data-mining approaches // Advances in Life Course Research. V.10: 283-314.

RMEZ [RLMS] (2013). Rossiyskiy monitoring ekonomicheskogo polozheniya i zdorov'ya naseleniya NIU-VSHE (22-ya volna), provodimyy NIU «Vysshaya shkola ekonomiki» i ZAO «Demoskop» pri uchastii Tsentra narodonaseleniya Universiteta Severnoy Karoliny v Chapel Khille i Instituta sotsiologii RAN [Russian monitoring of the economic situation and public health HSE (22th wave) conducted by NIU "Higher School of Economics" and CJSC "Demoscope" with the participation of the Center at the University of North Carolina at Chapel Hill, the population and the Institute of Sociology]. URL: http://www.hse.ru/rlms (date accessed: 20.02.2015).

Rozhdestvenskaya E. (2012). Biograficheskiy metod v sociologii [Biographical method in sociology] // Vysshaya Shkola Economiki [HSE Publishing House]: 381.

Sampson R.J., J.H. Laub (1996). Socioeconomic achievement in the life course of disadvantaged men: Military service as a turning point, circa 1940-1965 // American Sociological Review. V.61. №3: 347-367. 
Shearer D. (1998). Private armies and military intervention. London: Adelphi Paper: 316.

Smirnov A. (2009). Sluzhba v armii poteryannoe vremya [Military service as waste of time] // Sociologicheskie Issledovaniya [Sociological studies]. V.12: 100-108.

Suhanova M. (2014). Otnoshenie yunoshey k sluzhbe v armii [Attitude of young men to military services] // Materialy IX mezhdunarodnoy nauchno-prakticheskoy konferentsii prepodavateley i studentov «Chelovek v XXI veke» [Proceedings of the IX International scientific-practical conference of teachers and students "Man in the XXI century man"]. Obninsk: 78-79.

Van de Kaa D.J. (1987). Europe's second demographic transition // Population Bulletin. V.42: 3-57.

Van Schellen M., R. Apel, P. Nieuwbeerta (2012). "Because you're mine, I walk the line"? Marriage, spousal criminality, and criminal offending over the life course // Journal of quantitative criminology. V.28. №4: 701-723.

Zaharov S. (2007). Demograficheskie obsledovaniya naseleniya: proshloe, nastoyashee, budushee [Demographic Surveys: Past, Present, Future] // Roditeli i deti, muzhchiny i zhenshiny v sem'ei obshestve [Parents and children, men and women in family and society] / T. Maleva, O. Sinyavskaia. M.: NISP: 640. 


\section{ПРИЛОЖЕНИЕ}

Таблица П-1. Группировка событий в статусы (с указанием аббревиатур, обозначающих каждый статус)

\begin{tabular}{|c|c|c|c|c|c|c|}
\hline \multirow{3}{*}{$\begin{array}{l}\text { Социоэкономические } \\
\text { события }\end{array}$} & \multicolumn{6}{|c|}{ Демографические события } \\
\hline & \multicolumn{3}{|c|}{ нет детей } & \multicolumn{3}{|c|}{1 ребенок } \\
\hline & одинок & 1 партнер & 1 брак & одинок & 1 партнер & 1 брак \\
\hline & $\mathrm{SCO0}$ & & & & & \\
\hline Нет события или & SCOL & & & & & \\
\hline \multirow[t]{2}{*}{1 событие } & $\mathrm{SCOJ}$ & & & & & \\
\hline & SC0E & $\mathrm{P} 1 \mathrm{C} 01$ & M1C01 & SC11 & $\mathrm{P} 1 \mathrm{C} 11$ & M1C11 \\
\hline Отделение > событие & SCOL+ & P1C0L+ & M1C0L+ & SC1L+ & P1C1L+ & M1C1L+ \\
\hline Работа > событие & $\mathrm{SC} 0 \mathrm{~J}+$ & $\mathrm{P} 1 \mathrm{C} 0 \mathrm{~J}+$ & $\mathrm{M} 1 \mathrm{C} 0 \mathrm{~J}+$ & SC1J+ & $\mathrm{P} 1 \mathrm{C} 1 \mathrm{~J}+$ & M1C1J+ \\
\hline Образование > событие & $\mathrm{SCOE}+$ & $\mathrm{P} 1 \mathrm{C} 0 \mathrm{E}+$ & $\mathrm{M} 1 \mathrm{C} 0 \mathrm{E}+$ & SC1E+ & P1C1E+ & M1C1E+ \\
\hline 2 события одновременно & $\mathrm{SC} 02$ & $\mathrm{P} 1 \mathrm{C} 02$ & M1C02 & $\mathrm{SC} 12$ & $\mathrm{P} 1 \mathrm{C} 12$ & M1C12 \\
\hline 2 события > отделение & $\mathrm{SC} 0++\mathrm{L}$ & $\mathrm{P} 1 \mathrm{C} 0++\mathrm{L}$ & $\mathrm{M} 1 \mathrm{C} 0++\mathrm{L}$ & $\mathrm{SC} 1++\mathrm{L}$ & $\mathrm{P} 1 \mathrm{C} 1++\mathrm{L}$ & $\mathrm{M} 1 \mathrm{C} 1++\mathrm{L}$ \\
\hline 2 события > работа & $\mathrm{SCO}++\mathrm{J}$ & $\mathrm{P} 1 \mathrm{C} 0++\mathrm{J}$ & $\mathrm{M} 1 \mathrm{C} 0++\mathrm{J}$ & $\mathrm{SC} 1++\mathrm{J}$ & $\mathrm{P} 1 \mathrm{C} 1++\mathrm{J}$ & $\mathrm{M} 1 \mathrm{C} 1++\mathrm{J}$ \\
\hline 2 события > образование & $\mathrm{SC} 0++\mathrm{E}$ & $\mathrm{P} 1 \mathrm{C} 0++\mathrm{E}$ & $\mathrm{M} 1 \mathrm{C} 0++\mathrm{E}$ & $\mathrm{SC} 1++\mathrm{E}$ & $\mathrm{P} 1 \mathrm{C} 1++\mathrm{E}$ & $\mathrm{M} 1 \mathrm{C} 1++\mathrm{E}$ \\
\hline 3 события одновременно & $\mathrm{SCO} 3$ & $\mathrm{P} 1 \mathrm{C} 03$ & M1C03 & $\mathrm{SC} 13$ & $\mathrm{P} 1 \mathrm{C} 13$ & M1C13 \\
\hline Цензурирование & & & & & & \\
\hline
\end{tabular}

Таблица П-2. Ранжирование статусов от самого длительного до самого короткого для всех мужчин, для служивших и для не служивших в армии

\begin{tabular}{|c|c|c|c|c|c|c|}
\hline \multirow[b]{2}{*}{ № пா } & \multicolumn{2}{|c|}{ Bce } & \multicolumn{2}{|c|}{ Служившие в армии } & \multicolumn{2}{|c|}{ Не служившие в армии } \\
\hline & статус & $\begin{array}{c}\text { средняя } \\
\text { длительность, } \\
\text { мес. }\end{array}$ & статус & $\begin{array}{c}\text { средняя } \\
\text { длительность, } \\
\text { мес. }\end{array}$ & статус & $\begin{array}{c}\text { средняя } \\
\text { длительность, } \\
\text { мес. }\end{array}$ \\
\hline 1 & SC00 & 38,54 & $\mathrm{SCO0}$ & 38,07 & SC00 & 39,10 \\
\hline 2 & $\mathrm{SCOE}+$ & 14,37 & $\mathrm{M} 1 \mathrm{C} 1++\mathrm{L}$ & 16,88 & SCOE & 13,47 \\
\hline 3 & $\mathrm{SCOE}$ & 13,43 & $\mathrm{SCOE}+$ & 16,08 & $\mathrm{SCOE}+$ & 12,37 \\
\hline 4 & $\mathrm{M} 1 \mathrm{C} 1++\mathrm{L}$ & 13,32 & SCOE & 13,40 & $\mathrm{M} 1 \mathrm{C} 1++\mathrm{L}$ & 9,16 \\
\hline 5 & $\mathrm{M} 1 \mathrm{C} 1++\mathrm{J}$ & 8,05 & $\mathrm{M} 1 \mathrm{C} 1++\mathrm{J}$ & 10,46 & SCOJ+ & 7,57 \\
\hline 6 & $\mathrm{SCOJ}+$ & 6,87 & $\mathrm{SC} 0++\mathrm{J}$ & 8,98 & $\mathrm{SC} 0++\mathrm{L}$ & 5,76 \\
\hline 7 & $\mathrm{SC} 0++\mathrm{J}$ & 6,75 & $\mathrm{M} 1 \mathrm{C} 1++\mathrm{E}$ & 7,25 & $\mathrm{M} 1 \mathrm{C} 1++\mathrm{J}$ & 5,23 \\
\hline 8 & $\mathrm{SC} 0++\mathrm{L}$ & 6,39 & $\mathrm{SC} 0++\mathrm{L}$ & 6,92 & $\mathrm{P} 1 \mathrm{C} 01$ & 4,44 \\
\hline 9 & $\mathrm{M} 1 \mathrm{C} 1++\mathrm{E}$ & 5,70 & SCOL & 6,74 & SCOL & 4,37 \\
\hline 10 & SCOL & 5,65 & $\mathrm{SCOJ}+$ & 6,28 & $\mathrm{SC} 0++\mathrm{J}$ & 4,14 \\
\hline 11 & $\mathrm{P} 1 \mathrm{C} 0++\mathrm{L}$ & 4,31 & $\mathrm{M} 1 \mathrm{C} 0++\mathrm{L}$ & 5,26 & $\mathrm{M} 1 \mathrm{C} 1++\mathrm{E}$ & 3,89 \\
\hline 12 & $\mathrm{P} 1 \mathrm{C} 01$ & 4,26 & $\mathrm{P} 1 \mathrm{C} 0++\mathrm{L}$ & 4,71 & $\mathrm{P} 1 \mathrm{C} 0++\mathrm{L}$ & 3,84 \\
\hline 13 & $\mathrm{M} 1 \mathrm{C} 0++\mathrm{L}$ & 4,09 & $\mathrm{P} 1 \mathrm{C} 01$ & 4,11 & $\mathrm{SCOJ}$ & 3,83 \\
\hline 14 & $\mathrm{SC} 0++\mathrm{E}$ & 3,58 & $\mathrm{SC} 0++\mathrm{E}$ & 4,01 & $\mathrm{SC} 0++\mathrm{E}$ & 3,08 \\
\hline 15 & $\mathrm{SCOJ}$ & 3,20 & $\mathrm{P} 1 \mathrm{C} 0++\mathrm{J}$ & 3,58 & $\mathrm{M} 1 \mathrm{C} 0++\mathrm{L}$ & 2,73 \\
\hline 16 & $\mathrm{P} 1 \mathrm{C} 0++\mathrm{J}$ & 3,00 & $\mathrm{P} 1 \mathrm{C} 0 \mathrm{E}+$ & 3,39 & P1C0E+ & 2,40 \\
\hline 17 & $\mathrm{P} 1 \mathrm{C} 0 \mathrm{E}+$ & 2,93 & SCOL+ & 3,27 & $\mathrm{M} 1 \mathrm{C} 0++\mathrm{J}$ & 2,38 \\
\hline 18 & $\mathrm{M} 1 \mathrm{C} 0++\mathrm{J}$ & 2,83 & $\mathrm{M} 1 \mathrm{C} 0++\mathrm{J}$ & 3,21 & $\mathrm{P} 1 \mathrm{C} 0++\mathrm{E}$ & 2,33 \\
\hline 19 & SCOL+ & 2,58 & M1C1E+ & 3,07 & $\mathrm{P} 1 \mathrm{C} 0++\mathrm{J}$ & 2,32 \\
\hline 20 & $\mathrm{P} 1 \mathrm{C} 1++\mathrm{L}$ & 2,44 & $\mathrm{P} 1 \mathrm{C} 1++\mathrm{L}$ & 2,83 & $\mathrm{P} 1 \mathrm{C} 1++\mathrm{L}$ & 1,98 \\
\hline 21 & $\mathrm{P} 1 \mathrm{C} 0++\mathrm{E}$ & 2,21 & $\mathrm{SCOJ}$ & 2,67 & $\mathrm{P} 1 \mathrm{C} 0 \mathrm{~J}+$ & 1,92 \\
\hline 22 & M1C1E+ & 2,18 & $\mathrm{M} 1 \mathrm{C} 0++\mathrm{E}$ & 2,18 & SCOL+ & 1,78 \\
\hline 23 & $\mathrm{M} 1 \mathrm{C} 0++\mathrm{E}$ & 1,91 & $\mathrm{P} 1 \mathrm{C} 0++\mathrm{E}$ & 2,10 & $\mathrm{M} 1 \mathrm{C} 0++\mathrm{E}$ & 1,60 \\
\hline 24 & $\mathrm{P} 1 \mathrm{C} 0 \mathrm{~J}+$ & 1,50 & $\mathrm{P} 1 \mathrm{C} 1++\mathrm{J}$ & 1,92 & $\mathrm{SC} 1++\mathrm{L}$ & 1,27 \\
\hline 25 & $\mathrm{SC} 1++\mathrm{L}$ & 1,30 & $\mathrm{SC} 1++\mathrm{J}$ & 1,63 & $\mathrm{SC} 02$ & 1,18 \\
\hline 26 & $\mathrm{SC} 1++\mathrm{J}$ & 1,29 & M1C0E+ & 1,59 & M1C1E+ & 1,15 \\
\hline 27 & $\mathrm{P} 1 \mathrm{C} 1++\mathrm{J}$ & 1,24 & M1C1J+ & 1,44 & P1C0L+ & 0,99 \\
\hline 28 & M1C1J+ & 1,16 & $\mathrm{SC} 1++\mathrm{L}$ & 1,33 & M1C13 & 0,90 \\
\hline 29 & $\mathrm{M} 1 \mathrm{COE}+$ & 1,16 & $\mathrm{P} 1 \mathrm{C} 0 \mathrm{~J}+$ & 1,14 & $\mathrm{SC} 1++\mathrm{J}$ & 0,90 \\
\hline 30 & M1C13 & 0,90 & $\mathrm{SC} 03$ & 0,98 & $\mathrm{P} 1 \mathrm{C} 03$ & 0,89 \\
\hline
\end{tabular}




\begin{tabular}{|c|c|c|c|c|c|c|}
\hline \multirow[b]{2}{*}{ № пா } & \multicolumn{2}{|c|}{ Bce } & \multicolumn{2}{|c|}{ Служившие в армии } & \multicolumn{2}{|c|}{ Не служившие в армии } \\
\hline & статус & $\begin{array}{c}\text { средняя } \\
\text { длительность, } \\
\text { мес. }\end{array}$ & статус & $\begin{array}{c}\text { средняя } \\
\text { длительность, } \\
\text { мес. }\end{array}$ & статус & $\begin{array}{c}\text { средняя } \\
\text { длительность, } \\
\text { мес. }\end{array}$ \\
\hline 31 & $\mathrm{SC} 02$ & 0,86 & M1C1L+ & 0,96 & M1C1J+ & 0,84 \\
\hline 32 & $\mathrm{SC} 03$ & 0,76 & SC1E+ & 0,90 & $\mathrm{P} 1 \mathrm{C} 1++\mathrm{E}$ & 0,79 \\
\hline 33 & $\mathrm{P} 1 \mathrm{C} 1++\mathrm{E}$ & 0,75 & M1C13 & 0,90 & M1C0E+ & 0,66 \\
\hline 34 & P1C0L+ & 0,74 & M1C01 & 0,80 & $\mathrm{SC} 1++\mathrm{E}$ & 0,61 \\
\hline 35 & $\mathrm{SC} 1++\mathrm{E}$ & 0,71 & $\mathrm{SC} 1++\mathrm{E}$ & 0,80 & M1C01 & 0,56 \\
\hline 36 & M1C01 & 0,69 & $\mathrm{P} 1 \mathrm{C} 1++\mathrm{E}$ & 0,71 & $\mathrm{M} 1 \mathrm{C} 03$ & 0,50 \\
\hline 37 & M1C1L+ & 0,66 & $\mathrm{SC} 02$ & 0,58 & $\mathrm{SC} 03$ & 0,49 \\
\hline 38 & $\mathrm{P} 1 \mathrm{C} 03$ & 0,62 & SC1J+ & 0,57 & M1C0L+ & 0,48 \\
\hline 39 & SC1E+ & 0,59 & M1C11 & 0,56 & $\mathrm{P} 1 \mathrm{C} 1++\mathrm{J}$ & 0,44 \\
\hline 40 & M1C0L+ & 0,49 & M1C0J+ & 0,55 & P1C1E+ & 0,37 \\
\hline 41 & $\mathrm{M} 1 \mathrm{C} 0 \mathrm{~J}+$ & 0,46 & P1C0L+ & 0,53 & $\mathrm{M} 1 \mathrm{C} 0 \mathrm{~J}+$ & 0,36 \\
\hline 42 & SC1J+ & 0,43 & SC11 & 0,51 & M1C1L+ & 0,32 \\
\hline 43 & M1C11 & 0,42 & M1C0L+ & 0,50 & SC11 & 0,29 \\
\hline 44 & SC11 & 0,41 & P1C03 & 0,39 & SC1J+ & 0,27 \\
\hline 45 & P1C1E+ & 0,35 & P1C1E+ & 0,33 & M1C11 & 0,25 \\
\hline 46 & M1C03 & 0,34 & P1C11 & 0,25 & SC1E+ & 0,22 \\
\hline 47 & P1C11 & 0,21 & M1C03 & 0,20 & $\mathrm{P} 1 \mathrm{C} 1 \mathrm{~J}+$ & 0,21 \\
\hline 48 & SC13 & 0,15 & SC13 & 0,19 & $\mathrm{P} 1 \mathrm{C} 11$ & 0,16 \\
\hline 49 & $\mathrm{P} 1 \mathrm{C} 02$ & 0,15 & P1C1L+ & 0,16 & $\mathrm{P} 1 \mathrm{C} 02$ & 0,15 \\
\hline 50 & P1C1J+ & 0,14 & $\mathrm{P} 1 \mathrm{C} 02$ & 0,15 & SC1L+ & 0,14 \\
\hline 51 & SC1L+ & 0,13 & SC1L+ & 0,12 & SC13 & 0,10 \\
\hline 52 & P1C1L+ & 0,09 & P1C1J+ & 0,07 & M1C12 & 0,04 \\
\hline 53 & $\mathrm{M} 1 \mathrm{C} 02$ & 0,05 & M1C02 & 0,07 & P1C13 & 0,04 \\
\hline 54 & M1C12 & 0,03 & M1C12 & 0,02 & $\mathrm{M} 1 \mathrm{C} 02$ & 0,02 \\
\hline 55 & P1C13 & 0,02 & SC12 & 0,00 & $\mathrm{P} 1 \mathrm{C} 1 \mathrm{~L}+$ & 0,01 \\
\hline 56 & SC12 & 0,00 & $\mathrm{P} 1 \mathrm{C} 12$ & 0,00 & $\mathrm{SC} 12$ & 0,00 \\
\hline 57 & $\mathrm{P} 1 \mathrm{C} 12$ & 0,00 & P1C13 & 0,00 & $\mathrm{P} 1 \mathrm{C} 12$ & 0,00 \\
\hline
\end{tabular}

Таблица П-3. Ранжирование подпоследовательностей по частоте встречаемости у респондентов, служивших в армии

\begin{tabular}{|c|c|c|c|}
\hline № & Последовательность & $\begin{array}{c}\text { Доля в числе } \\
\text { служивших }\end{array}$ & Чел. \\
\hline 1 & $(\mathrm{SCO0})$ & 0,905 & 1005 \\
\hline 2 & $(\mathrm{SCO0})-(\mathrm{SCO}>\mathrm{SCOE})$ & 0,436 & 484 \\
\hline 3 & $(\mathrm{SCO}>>\mathrm{SCOE})$ & 0,436 & 484 \\
\hline 4 & $(\mathrm{SC} 0 \mathrm{E}>\mathrm{SC} 0 \mathrm{E}+)$ & 0,389 & 432 \\
\hline 5 & $(\mathrm{SCO0})-(\mathrm{SCOE}>\mathrm{SCOE}+)$ & 0,356 & 395 \\
\hline 6 & $(\mathrm{SCO0})-(\mathrm{SCO} 0>\mathrm{SCOE})-(\mathrm{SCOE}>\mathrm{SCOE}+)$ & 0,350 & 389 \\
\hline 7 & $(\mathrm{SC} 00>\mathrm{SC} 0 \mathrm{E})-(\mathrm{SC} 0 \mathrm{E}>\mathrm{SC} 0 \mathrm{E}+)$ & 0,350 & 389 \\
\hline 8 & $(\mathrm{SCO}>\mathrm{SCOL})$ & 0,194 & 216 \\
\hline 9 & $(\mathrm{SCO0})-(\mathrm{SCO0}>\mathrm{SCOL})$ & 0,194 & 215 \\
\hline 10 & $(\mathrm{SCOL}>\mathrm{SCOL}+)$ & 0,166 & 184 \\
\hline 11 & $(\mathrm{SCO0})-(\mathrm{SCO0}>\mathrm{SCOJ})$ & 0,163 & 181 \\
\hline 12 & $(\mathrm{SCO}>\mathrm{SCOJ})$ & 0,163 & 181 \\
\hline 13 & $(\mathrm{M} 1 \mathrm{C} 0++\mathrm{L}>\mathrm{M} 1 \mathrm{C} 1++\mathrm{L})$ & 0,157 & 174 \\
\hline 14 & $(\mathrm{SCOO})-(\mathrm{SCO}>\mathrm{SCOL})-(\mathrm{SCOL}>\mathrm{SCOL}+)$ & 0,150 & 167 \\
\hline 15 & $(\mathrm{SCOO})-(\mathrm{SCOL}>\mathrm{SCOL}+)$ & 0,150 & 167 \\
\hline 16 & $(\mathrm{SCO}>\mathrm{SCOL})-(\mathrm{SCOL}>\mathrm{SCOL}+)$ & 0,150 & 167 \\
\hline 17 & $(\mathrm{SCO0})-(\mathrm{M} 1 \mathrm{CO}++\mathrm{L}>\mathrm{M} 1 \mathrm{C} 1++\mathrm{L})$ & 0,143 & 159 \\
\hline 18 & $(\mathrm{SCOJ}>\mathrm{SCOJ}+)$ & 0,134 & 149 \\
\hline 19 & $(\mathrm{SCO0})-(\mathrm{SCO0}>\mathrm{SCOJ})-(\mathrm{SCOJ}>\mathrm{SCOJ}+)$ & 0,125 & 139 \\
\hline 20 & $(\mathrm{SCO})-(\mathrm{SCOJ}>\mathrm{SCOJ}+)$ & 0,125 & 139 \\
\hline 21 & $(\mathrm{SCO0}>\mathrm{SCOJ})-(\mathrm{SCOJ}>\mathrm{SCOJ}+)$ & 0,125 & 139 \\
\hline 22 & $(\mathrm{SCOE}+>\mathrm{P} 1 \mathrm{COE}+)$ & 0,098 & 109 \\
\hline 23 & $(\mathrm{SCO0}>\mathrm{P} 1 \mathrm{CO1})$ & 0,096 & 107 \\
\hline 24 & $(\mathrm{SC} 0 \mathrm{E}+>\mathrm{SC} 0++\mathrm{L})$ & 0,095 & 105 \\
\hline
\end{tabular}




\begin{tabular}{|c|c|c|c|}
\hline № & Последовательность & $\begin{array}{c}\text { Доля в числе } \\
\text { служивших }\end{array}$ & Чел. \\
\hline 25 & $(\mathrm{SC00})-(\mathrm{SC00}>\mathrm{P1C01})$ & 0,092 & 102 \\
\hline 26 & $(\mathrm{SCOE}>\mathrm{SC} 0 \mathrm{E}+)-(\mathrm{SCOE}+>\mathrm{SC} 0++\mathrm{L})$ & 0,092 & 102 \\
\hline 27 & $(\mathrm{SCOE}>\mathrm{SC} 0 \mathrm{E}+)-(\mathrm{M} 1 \mathrm{C} 0++\mathrm{L}>\mathrm{M} 1 \mathrm{C} 1++\mathrm{L})$ & 0,087 & 97 \\
\hline 28 & $(\mathrm{SCOE}>\mathrm{SCOE}+)-(\mathrm{SCOE}+>\mathrm{P} 1 \mathrm{COE}+)$ & 0,086 & 96 \\
\hline 29 & $(\mathrm{SCO0})-(\mathrm{SC} 00>\mathrm{SC} 0 \mathrm{E})-(\mathrm{M} 1 \mathrm{C} 0++\mathrm{L}>\mathrm{M} 1 \mathrm{C} 1++\mathrm{L})$ & 0,086 & 95 \\
\hline 30 & $(\mathrm{SCO0})-(\mathrm{SCOE}+>\mathrm{P} 1 \mathrm{COE}+)$ & 0,086 & 95 \\
\hline 31 & $(\mathrm{SC} 00>\mathrm{SC} 0 \mathrm{E})-(\mathrm{M} 1 \mathrm{C} 0++\mathrm{L}>\mathrm{M} 1 \mathrm{C} 1++\mathrm{L})$ & 0,086 & 95 \\
\hline 32 & $(\mathrm{SC} 00)-(\mathrm{SCOE}+>\mathrm{SC} 0++\mathrm{L})$ & 0,085 & 94 \\
\hline 33 & $(\mathrm{SC} 00)-(\mathrm{SC} 00>\mathrm{SC} 0 \mathrm{E})-(\mathrm{SCOE}+>\mathrm{SC} 0++\mathrm{L})$ & 0,084 & 93 \\
\hline 34 & $(\mathrm{SCO0})-(\mathrm{SCOE}>\mathrm{SC} 0 \mathrm{E}+)-(\mathrm{M} 1 \mathrm{C} 0++\mathrm{L}>\mathrm{M1C} 1++\mathrm{L})$ & 0,084 & 93 \\
\hline 35 & $(\mathrm{SC} 00)-(\mathrm{SCOE}>\mathrm{SCOE}+)-(\mathrm{SCOE}+>\mathrm{SC} 0++\mathrm{L})$ & 0,084 & 93 \\
\hline 36 & $(\mathrm{SC} 00>\mathrm{SC} 0 \mathrm{E})-(\mathrm{SC} 0 \mathrm{E}+>\mathrm{SC} 0++\mathrm{L})$ & 0,084 & 93 \\
\hline 37 & $(\mathrm{M} 1 \mathrm{C} 0++\mathrm{J}>\mathrm{M} 1 \mathrm{C} 1++\mathrm{J})$ & 0,083 & 92 \\
\hline 38 & $(\mathrm{SCO0})-(\mathrm{SC} 00>\mathrm{SC} 0 \mathrm{E})-(\mathrm{SCOE}>\mathrm{SC} 0 \mathrm{E}+)-(\mathrm{SC} 0 \mathrm{E}+>\mathrm{SC} 0++\mathrm{L})$ & 0,083 & 92 \\
\hline 39 & $(\mathrm{SC} 00>\mathrm{SC} 0 \mathrm{E})-(\mathrm{SC} 0 \mathrm{E}>\mathrm{SC} 0 \mathrm{E}+)-(\mathrm{SC} 0 \mathrm{E}+>\mathrm{SC} 0++\mathrm{L})$ & 0,083 & 92 \\
\hline 40 & $(\mathrm{P} 1 \mathrm{C} 0++\mathrm{L}>\mathrm{M} 1 \mathrm{C} 0++\mathrm{L})$ & 0,080 & 89 \\
\hline 41 & $(\mathrm{SCO0})-(\mathrm{SCO0}>\mathrm{SCOE})-(\mathrm{SCOE}>\mathrm{SC} 0 \mathrm{E}+)-(\mathrm{M} 1 \mathrm{C} 0++\mathrm{L}>\mathrm{M} 1 \mathrm{C} 1++\mathrm{L})$ & 0,080 & 89 \\
\hline 42 & $(\mathrm{SC} 00>\mathrm{SC} 0 \mathrm{E})-(\mathrm{SC} 0 \mathrm{E}>\mathrm{SC} 0 \mathrm{E}+)-(\mathrm{M1C0}++\mathrm{L}>\mathrm{M1C1}++\mathrm{L})$ & 0,080 & 89 \\
\hline 43 & $(\mathrm{SCO0})-(\mathrm{SCO0}>\mathrm{SCOE})-(\mathrm{SCOE}+>\mathrm{P} 1 \mathrm{COE}+)$ & 0,077 & 86 \\
\hline 44 & $(\mathrm{SCO0})-(\mathrm{SCOE}>\mathrm{SCOE}+)-(\mathrm{SCOE}+>\mathrm{P} 1 \mathrm{C} 0 \mathrm{E}+)$ & 0,077 & 86 \\
\hline 45 & $(\mathrm{SCO0}>\mathrm{SCOE})-(\mathrm{SCOE}+>\mathrm{P} 1 \mathrm{COE}+)$ & 0,077 & 86 \\
\hline 46 & $(\mathrm{SCOL}+>\mathrm{SC} 0++\mathrm{J})$ & 0,076 & 84 \\
\hline 47 & $(\mathrm{SCO0})-(\mathrm{M1C0}++\mathrm{J}>\mathrm{M} 1 \mathrm{C} 1++\mathrm{J})$ & 0,075 & 83 \\
\hline 48 & $(\mathrm{SCO0})-(\mathrm{SC00}>\mathrm{SCOE})-(\mathrm{SCOE}>\mathrm{SCOE}+)-(\mathrm{SCOE}+>\mathrm{P} 1 \mathrm{C} 0 \mathrm{E}+)$ & 0,075 & 83 \\
\hline 49 & $(\mathrm{SCO0}>\mathrm{SCOE})-(\mathrm{SC} 0 \mathrm{E}>\mathrm{SC} 0 \mathrm{E}+)-(\mathrm{SCOE}+>\mathrm{P} 1 \mathrm{COE}+)$ & 0,075 & 83 \\
\hline 50 & $(\mathrm{SCO}++\mathrm{L}>\mathrm{P} 1 \mathrm{CO}++\mathrm{L})$ & 0,074 & 82 \\
\hline
\end{tabular}

П-4. Ранжирование подпоследовательностей по частоте встречаемости у респондентов, не служивших в армии

\begin{tabular}{|c|c|c|c|}
\hline № & Последовательность & $\begin{array}{c}\text { Доля в числе не } \\
\text { служивших }\end{array}$ & Чел. \\
\hline 1 & $(\mathrm{SC} 00)$ & 0,924 & 879 \\
\hline 2 & $(\mathrm{SC} 00>\mathrm{SC} 0 \mathrm{E})$ & 0,441 & 419 \\
\hline 3 & $(\mathrm{SC} 00)-(\mathrm{SCO0}>\mathrm{SCOE})$ & 0,440 & 418 \\
\hline 4 & $(\mathrm{SCOE}>\mathrm{SCOE}+)$ & 0,306 & 291 \\
\hline 5 & $(\mathrm{SC} 00)-(\mathrm{SCOE}>\mathrm{SCOE}+)$ & 0,284 & 270 \\
\hline 6 & $(\mathrm{SC} 00>\mathrm{SC} 0 \mathrm{E})-(\mathrm{SCOE}>\mathrm{SC} 0 \mathrm{E}+)$ & 0,279 & 265 \\
\hline 7 & $(\mathrm{SC} 00)-(\mathrm{SC} 00>\mathrm{SC} 0 \mathrm{E})-(\mathrm{SC} 0 \mathrm{E}>\mathrm{SC} 0 \mathrm{E}+)$ & 0,278 & 264 \\
\hline 8 & $(\mathrm{SCO})-(\mathrm{SCO}>\mathrm{SCOJ})$ & 0,205 & 195 \\
\hline 9 & $(\mathrm{SC} 00>\mathrm{SC} 0 \mathrm{~J})$ & 0,205 & 195 \\
\hline 10 & $(\mathrm{SCOJ}>\mathrm{SCOJ}+)$ & 0,182 & 173 \\
\hline 11 & $(\mathrm{SCO})-(\mathrm{SCOJ}>\mathrm{SCOJ}+)$ & 0,171 & 163 \\
\hline 12 & $(\mathrm{SCO})-(\mathrm{SCO}>\mathrm{SCOJ})-(\mathrm{SCOJ}>\mathrm{SCOJ}+)$ & 0,170 & 162 \\
\hline 13 & $(\mathrm{SCO} 0>\mathrm{SC} 0 \mathrm{~J})-(\mathrm{SCOJ}>\mathrm{SCOJ}+)$ & 0,170 & 162 \\
\hline 14 & $(\mathrm{SC} 00)-(\mathrm{SCO}>\mathrm{SCOL})$ & 0,135 & 128 \\
\hline 15 & $(\mathrm{SCO}>\mathrm{SCOL})$ & 0,135 & 128 \\
\hline 16 & $(\mathrm{SCO0}>\mathrm{P} 1 \mathrm{C01})$ & 0,129 & 123 \\
\hline 17 & $(\mathrm{SC00})-(\mathrm{SCO0}>\mathrm{P} 1 \mathrm{C01})$ & 0,127 & 121 \\
\hline 18 & $(\mathrm{SCOL}>\mathrm{SCOL}+)$ & 0,111 & 106 \\
\hline 19 & $(\mathrm{SCO0})-(\mathrm{SCOL}>\mathrm{SCOL}+)$ & 0,102 & 97 \\
\hline 20 & $(\mathrm{SCO0})-(\mathrm{SCO} 0>\mathrm{SCOL})-(\mathrm{SCOL}>\mathrm{SCOL}+)$ & 0,101 & 96 \\
\hline 21 & $(\mathrm{SCO}>\mathrm{SCOL})-(\mathrm{SCOL}>\mathrm{SCOL}+)$ & 0,101 & 96 \\
\hline 22 & $(\mathrm{M} 1 \mathrm{C} 0++\mathrm{L}>\mathrm{M1C} 1++\mathrm{L})$ & 0,094 & 89 \\
\hline 23 & $(\mathrm{SC00})-(\mathrm{M1C0}++\mathrm{L}>\mathrm{M} 1 \mathrm{C} 1++\mathrm{L})$ & 0,084 & 80 \\
\hline 24 & $(\mathrm{SCOE}+>\mathrm{SC} 0++\mathrm{L})$ & 0,069 & 66 \\
\hline
\end{tabular}




\begin{tabular}{|c|c|c|c|}
\hline № & Последовательность & $\begin{array}{c}\text { Доля в числе не } \\
\text { служивших }\end{array}$ & Чел. \\
\hline 25 & $(\mathrm{P1C0}++\mathrm{L}>\mathrm{M1C0}++\mathrm{L})$ & 0,068 & 65 \\
\hline 26 & $(\mathrm{SCOE}>\mathrm{SC} 0 \mathrm{E}+)-(\mathrm{SCOE}+>\mathrm{SC} 0++\mathrm{L})$ & 0,067 & 64 \\
\hline 27 & $(\mathrm{SCOE}+>\mathrm{P1COE}+)$ & 0,066 & 63 \\
\hline 28 & $(\mathrm{SCO0})-(\mathrm{P} 1 \mathrm{CO}++\mathrm{L}>\mathrm{M} 1 \mathrm{CO}++\mathrm{L})$ & 0,064 & 61 \\
\hline 29 & $(\mathrm{SCOE}>\mathrm{SCOE}+)-(\mathrm{SCOE}+>\mathrm{P} 1 \mathrm{COE}+)$ & 0,063 & 60 \\
\hline 30 & $(\mathrm{SC} 00)-(\mathrm{SCOE}+>\mathrm{SC} 0++\mathrm{L})$ & 0,062 & 59 \\
\hline 31 & $(\mathrm{SC} 00)-(\mathrm{SCO}>\mathrm{SC} 0 \mathrm{E})-(\mathrm{SC} 0 \mathrm{E}+>\mathrm{SC} 0++\mathrm{L})$ & 0,061 & 58 \\
\hline 32 & $(\mathrm{SCO0})-(\mathrm{SCOE}+>\mathrm{P} 1 \mathrm{COE}+)$ & 0,061 & 58 \\
\hline 33 & $(\mathrm{SCO0})-(\mathrm{SCOE}>\mathrm{SCOE}+)-(\mathrm{SCOE}+>\mathrm{SC}++\mathrm{L})$ & 0,061 & 58 \\
\hline 34 & $(\mathrm{SCO}>\mathrm{SCOE})-(\mathrm{SCOE}+>\mathrm{SC} 0++\mathrm{L})$ & 0,061 & 58 \\
\hline 35 & $(\mathrm{SC} 00)-(\mathrm{SCO}>\mathrm{SC} 0 \mathrm{E})-(\mathrm{SCOE}>\mathrm{SC} 0 \mathrm{E}+)-(\mathrm{SC} 0 \mathrm{E}+>\mathrm{SC} 0++\mathrm{L})$ & 0,060 & 57 \\
\hline 36 & $(\mathrm{SCO}>\mathrm{SCOE})-(\mathrm{SCOE}>\mathrm{SCOE}+)-(\mathrm{SCOE}+>\mathrm{SC} 0++\mathrm{L})$ & 0,060 & 57 \\
\hline 37 & $(\mathrm{SCO}++\mathrm{L}>\mathrm{P} 1 \mathrm{CO}++\mathrm{L})$ & 0,059 & 56 \\
\hline 38 & $(\mathrm{SCO0}>\mathrm{SCOE})-(\mathrm{SCOE}+>\mathrm{P} 1 \mathrm{COE}+)$ & 0,059 & 56 \\
\hline 39 & $(\mathrm{SCO0})-(\mathrm{SCO0}>\mathrm{SCOE})-(\mathrm{SCOE}+>\mathrm{P} 1 \mathrm{COE}+)$ & 0,058 & 55 \\
\hline 40 & $(\mathrm{SCO0})-(\mathrm{SCOE}>\mathrm{SCOE}+)-(\mathrm{SCOE}+>\mathrm{P} 1 \mathrm{COE}+)$ & 0,058 & 55 \\
\hline 41 & $(\mathrm{SCO0}>\mathrm{SCOE})-(\mathrm{SCOE}>\mathrm{SCOE}+)-(\mathrm{SCOE}+>\mathrm{P1C} \mathrm{CE}+)$ & 0,056 & 53 \\
\hline 42 & $(\mathrm{SCO0})-(\mathrm{SCO0}>\mathrm{SCOE})-(\mathrm{SCOE}>\mathrm{SCOE}+)-(\mathrm{SCOE}+>\mathrm{P} 1 \mathrm{C} 0 \mathrm{E}+)$ & 0,055 & 52 \\
\hline 43 & $(\mathrm{SCO0})-(\mathrm{SCO}++\mathrm{L}>\mathrm{P} 1 \mathrm{CO}++\mathrm{L})$ & 0,053 & 50 \\
\hline 44 & $(\mathrm{SC} 0 \mathrm{~L}+>\mathrm{SC} 0++\mathrm{J})$ & 0,050 & 48 \\
\hline 45 & $(\mathrm{SCOL}>\mathrm{SCOL}+)-(\mathrm{SCOL}+>\mathrm{SC} 0++\mathrm{J})$ & 0,049 & 47 \\
\hline 46 & $(\mathrm{P} 1 \mathrm{C} 01>\mathrm{SC} 00)$ & 0,048 & 46 \\
\hline 47 & $(\mathrm{SC} 00)-(\mathrm{SCOL}+>\mathrm{SC} 0++\mathrm{J})$ & 0,047 & 45 \\
\hline 48 & $(\mathrm{P} 1 \mathrm{C} 0++\mathrm{L}>\mathrm{M} 1 \mathrm{C} 0++\mathrm{L})-(\mathrm{M} 1 \mathrm{C} 0++\mathrm{L}>\mathrm{M} 1 \mathrm{C} 1++\mathrm{L})$ & 0,046 & 44 \\
\hline 49 & $(\mathrm{P} 1 \mathrm{C} 01>\mathrm{P} 1 \mathrm{C} 0 \mathrm{~L}+)$ & 0,046 & 44 \\
\hline 50 & $(\mathrm{SC} 00)-(\mathrm{SCO}>\mathrm{SCOL})-(\mathrm{SCOL}+>\mathrm{SC} 0++\mathrm{J})$ & 0,046 & 44 \\
\hline
\end{tabular}

Примечание: Подпоследовательности, содержащие демографические события, обозначены жирным шрифтом. 